\title{
GUIA BÁSICO DE OBSERVAÇÃO: OBJETOS DO CÉU PROFUNDO
}

Tharcisio Alexandrino Caldeira Maria Lucivânia Souza dos Santos Matias Alves Martins

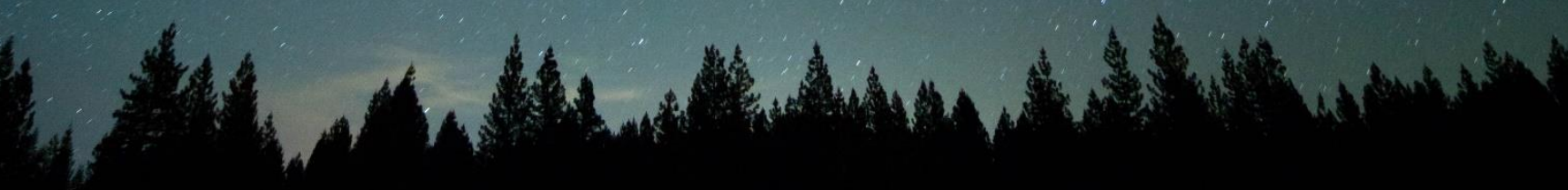


Esta obra não possui proteção DRM, podendo ser livremente distribuída. Entretanto, os autores solicitam que, em caso de utilização total ou parcial da obra, seja feita a devida citação:

CALDEIRA, T. A.; SANTOS, M. L. S.; MARTINS, M. A. Guia Básico de Observação: Objetos de Céu Profundo. Rio Pomba: Ed. do Autor, 2021. Disponível em: <www.casmastronomia.com.br/e-books-gratuitos>. Acesso em 19/04/2021.

Dados Internacionais de Catalogação na Publicação (CIP)

(Câmara Brasileira do Livro, SP, Brasil)

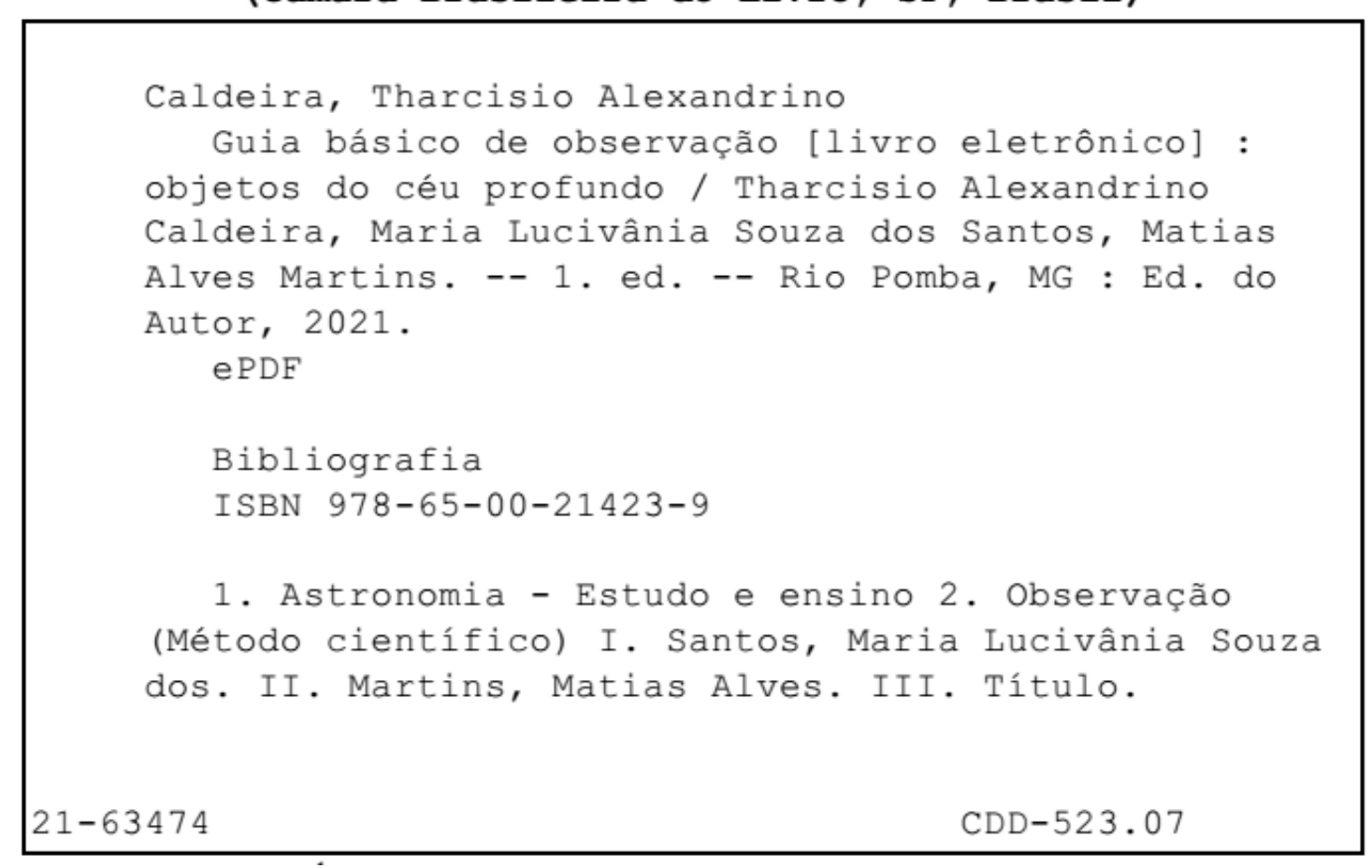




\section{SUMÁRIO}

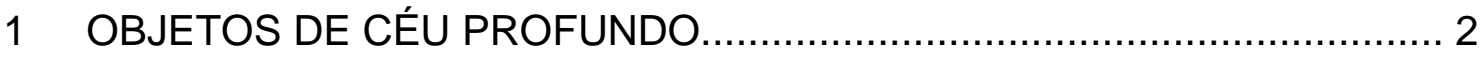

1.1 Catálogos de Objetos de Céu Profundo ..................................... 7

2 INICIANDO NA ASTRONOMIA OBSERVACIONAL $\ldots \ldots \ldots \ldots \ldots \ldots \ldots \ldots \ldots . . \ldots$

$2.1 \quad$ O que é a Astronomia Observacional.......................................... 10

2.2 Instrumentos de Observação .................................................. 10

2.3 Softwares e Astronomia Observacional..................................... 17

2.4 Poluição Luminosa, Escala de Bortle e Escala de Transparência ...... 24

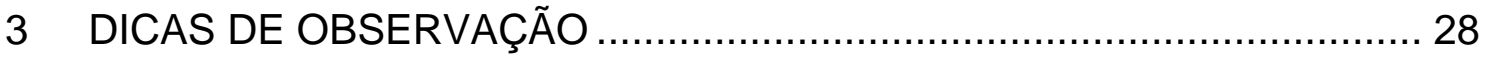

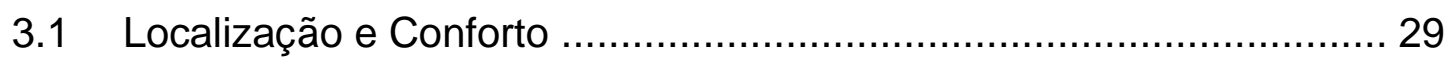

3.2 Planejamento das Observações............................................ 30

3.3 Equipamentos e Tecnologia ...................................................... 31

3.4 Técnicas de Observação........................................................ 32

3.5 Respeitando a Ciência Astronômica .............................................. 35

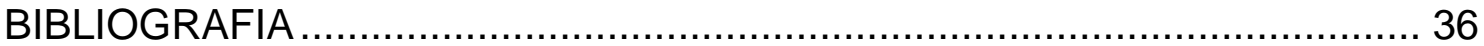




\section{CAPÍTULO 1:}

\section{OBJETOS DE CÉU PROFUNDO}




\section{Objetos de Céu Profundo - Deep-Sky Objects (DSO)}

A expressão "objetos de céu profundo" é utilizada por astrônomos amadores para aglomerados estelares, nebulosas e galáxias, com o objetivo de distinguir estes objetos de estrelas, planetas e satélites (MARAN, 2011). Não há um consenso sobre a origem do termo, mas diversas fontes indicam que ele se popularizou após a criação da coluna "Maravilhas do Céu Profundo" - em inglês, "Deep-Sky Wonders" - na Revista Sky\&Telescope, na década de 1940.

De acordo com Hendricks (2015), galáxias são aglomerados de gás, poeira e inúmeras estrelas, unidas pela força gravitacional. Nosso universo observável tem, de acordo com estimativas, 100 bilhões de galáxias. E as galáxias consideradas de pequeno porte possuem, em média, 100 bilhões de estrelas. Números impressionantes que demonstram nossa insignificância diante do universo...

As galáxias podem ser classificadas como espirais, elípticas e irregulares, de acordo com seu formato. Tal classificação foi, inicialmente, proposta pelo astrônomo Edwin Hubble (1889-1953), descreve as galáxias de acordo com o Quadro 1 a seguir:

\begin{tabular}{|c|c|c|}
\hline $\begin{array}{c}\text { Tipo de } \\
\text { Galáxia }\end{array}$ & Descrição & Exemplos \\
\hline Espiral & $\begin{array}{c}\text { Compostas por uma protuberância central, uma } \\
\text { auréola, um disco e braços espirais. Geralmente } \\
\text { os braços espirais contém material interestelar } \\
\text { espalhados entre eles. }\end{array}$ & Via Láctea e Andrômeda \\
\hline Elípticas & $\begin{array}{c}\text { Em geral, são compostas por estrelas “velhas" e } \\
\text { apresentam formato esférico ou elipsoide. Não } \\
\text { apresentam traços de braços espirais. Em } \\
\text { galáxias elípticas maiores, é comum a presença } \\
\text { de aglomerados estelares globulares. }\end{array}$ & Galáxia do Sombrero \\
\hline Irregulares & $\begin{array}{c}\text { Galáxias que não apresentam padrão visual } \\
\text { definido. Em geral, apresentam luminosidade } \\
\text { inferior em relação às galáxias espirais. Muitas } \\
\text { galáxias irregulares apresentam intensa } \\
\text { atividade de formação de novas estrelas. }\end{array}$ & Nuvens de Magalhães \\
\hline
\end{tabular}

Quadro 1: Classificação das Galáxias.

Fonte: adaptado de Franknoi et al. (2016).

As Figuras 1, 2 e 3 a seguir ilustram as características acima descritas. 


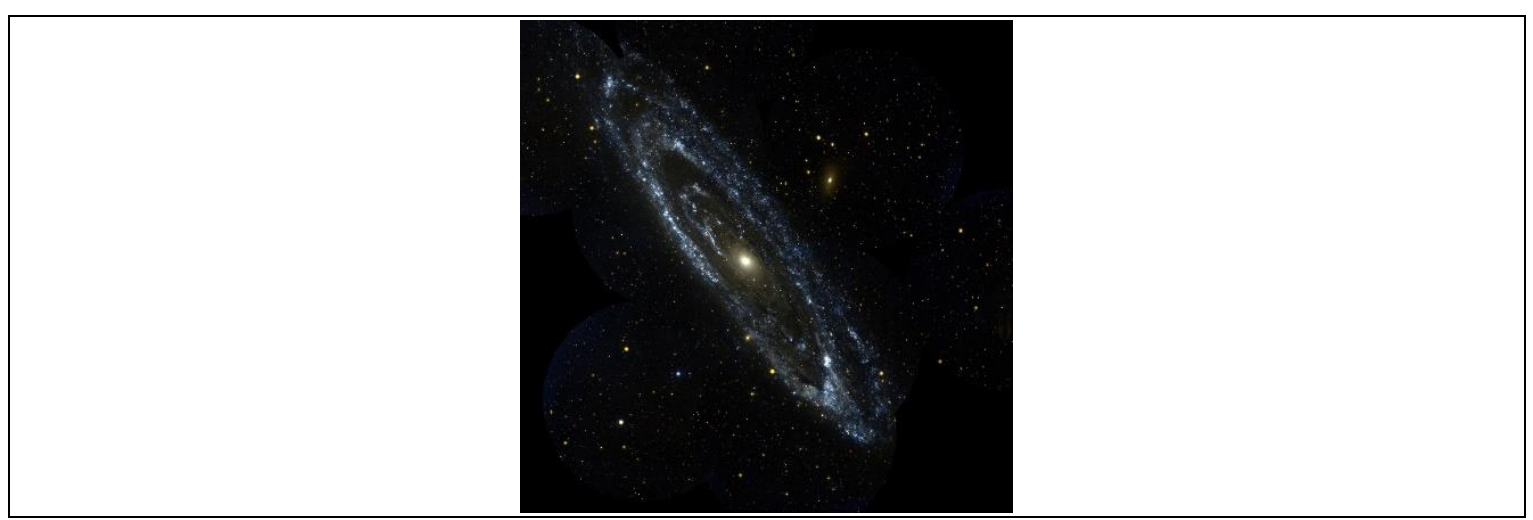

Figura 1: Galáxia de Andrômeda (espiral).

Fonte: NASA (2021a).

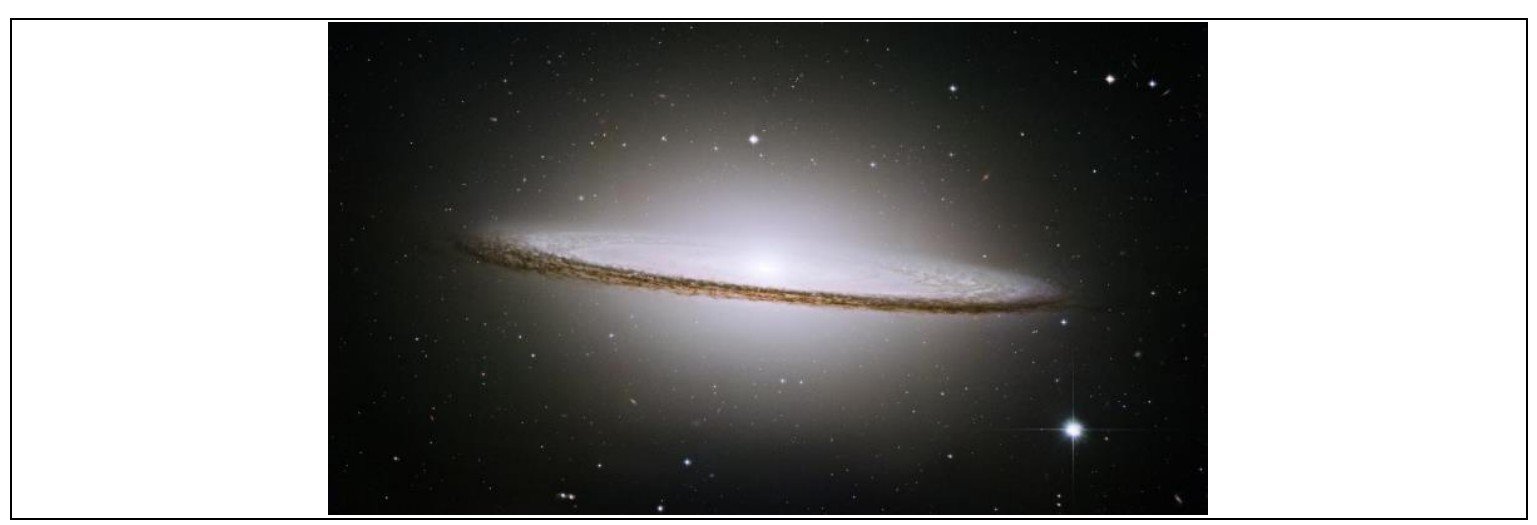

Figura 2: Galáxia do Sombrero (elíptica).

Fonte: NASA (2021b).

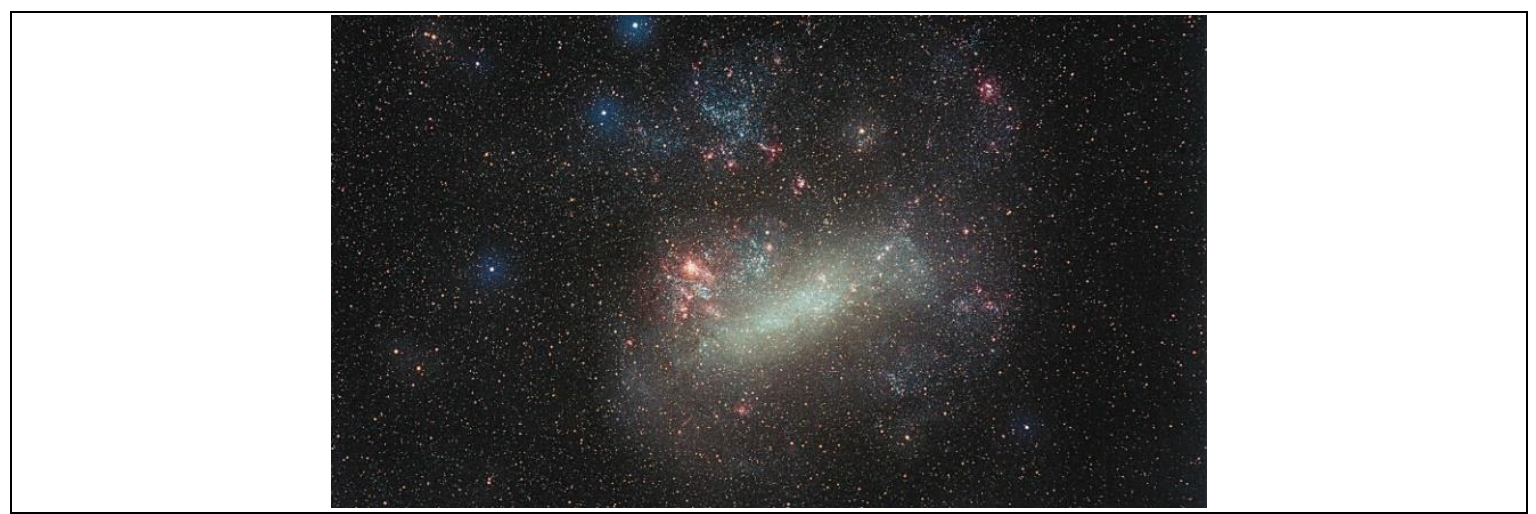

Figura 3: Grande Nuvem de Magalhães (irregular).

Fonte: EarthSky (2021).

Aglomerados estelares, por sua vez, são grupos de estrelas localizados no interior ou ao redor de uma galáxia. De acordo com Maran (2011), em geral, os aglomerados estelares são compostos por estrelas que se formaram juntas, permanecendo juntas em função da gravidade. Aglomerados estelares podem ser globulares (que apresentam grande concentração de estrelas no centro), abertos (que não apresentam concentração de estrelas no centro). A Figura 4 
exibe um aglomerado aberto, ao passo que a Figura 5 ilustra um aglomerado globular.

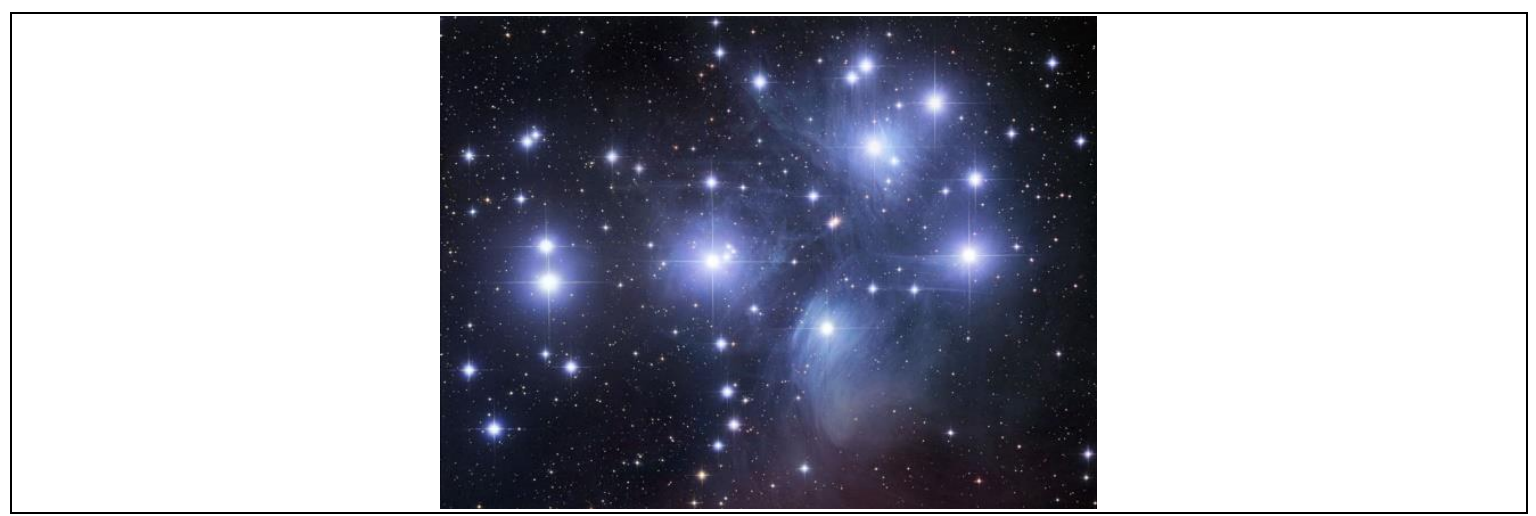

Figura 4: Aglomerado estelar aberto de Plêiades (M-45). Fonte: NASA (2006).

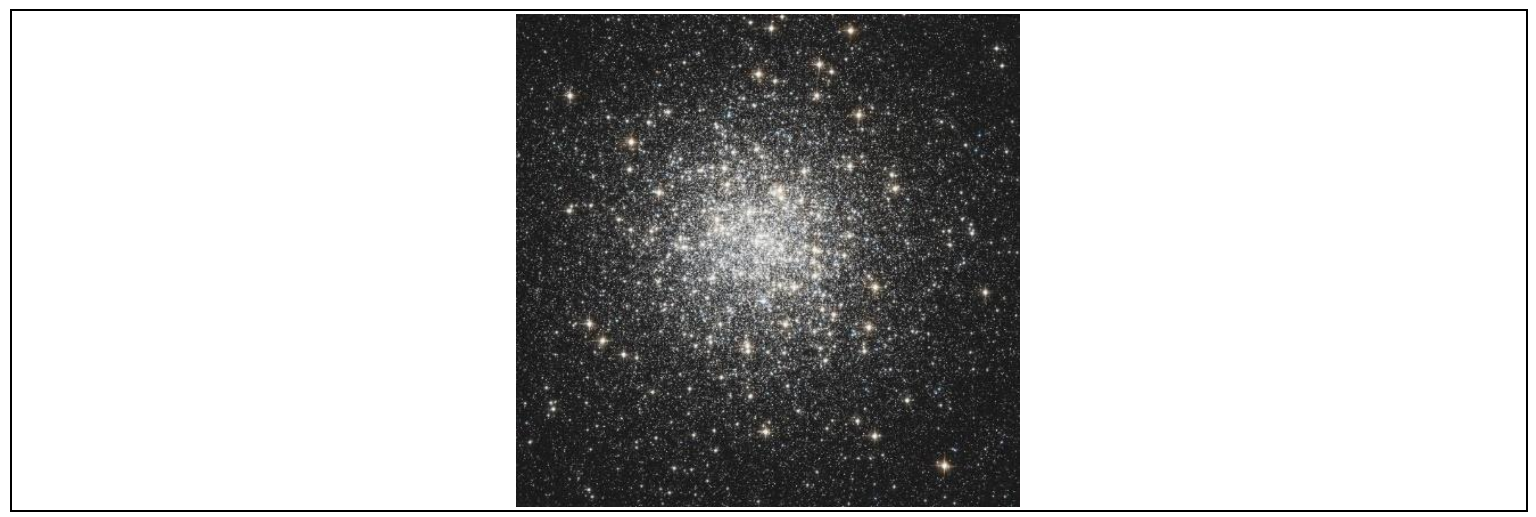

Figura 5: Aglomerado estelar globular M-3 (Messier 3).

Fonte: NASA (2017a).

Por fim, nebulosas são gigantescas nuvens de poeira estelar que, segundo Maran (2011), podem ser classificadas da seguinte forma: Nebulosas Região H-Il (onde as nuvens são de hidrogênio ionizado), Nebulosas de Reflexão (onde as nuvens são de hidrogênio neutro e frio, e a luminosidade é somente o reflexo de estrelas próximas), Nebulosas Escuras (nuvens de hidrogênio neutro e frio, mas sem estrelas próximas) e Nebulosas Planetárias (que ocorrem quando uma estrela expele suas camadas atmosféricas externas). As Figuras 6, 7, 8 e 9 ilustram cada tipo de nebulosa supracitada. 


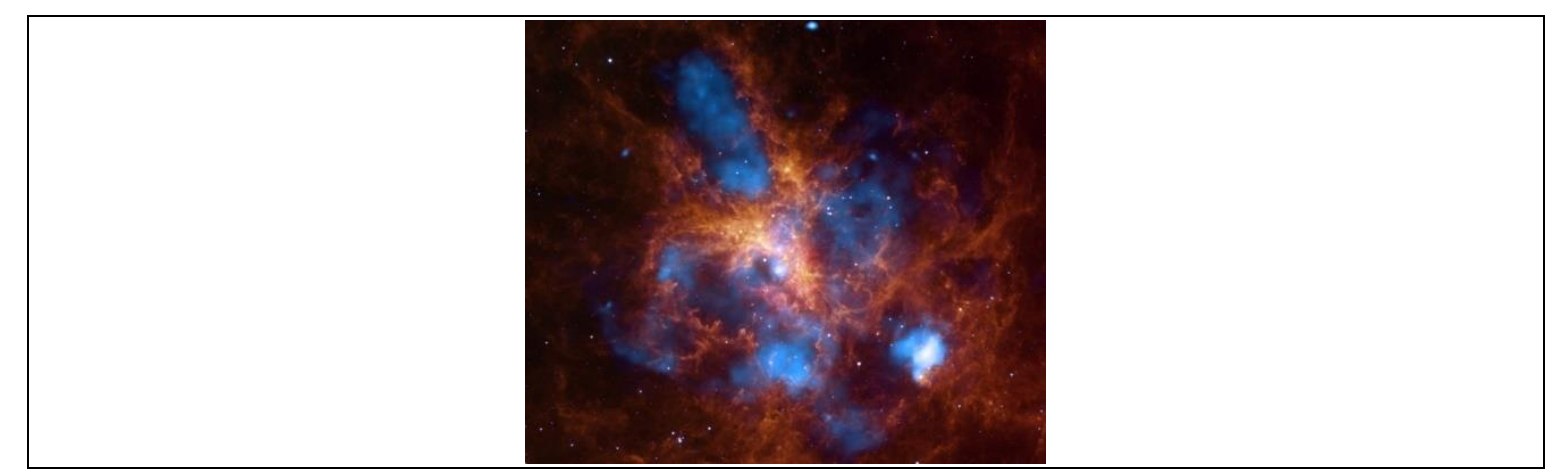

Figura 6: Nebulosa da Tarântula (Região H-II).

Fonte: NASA (2011).

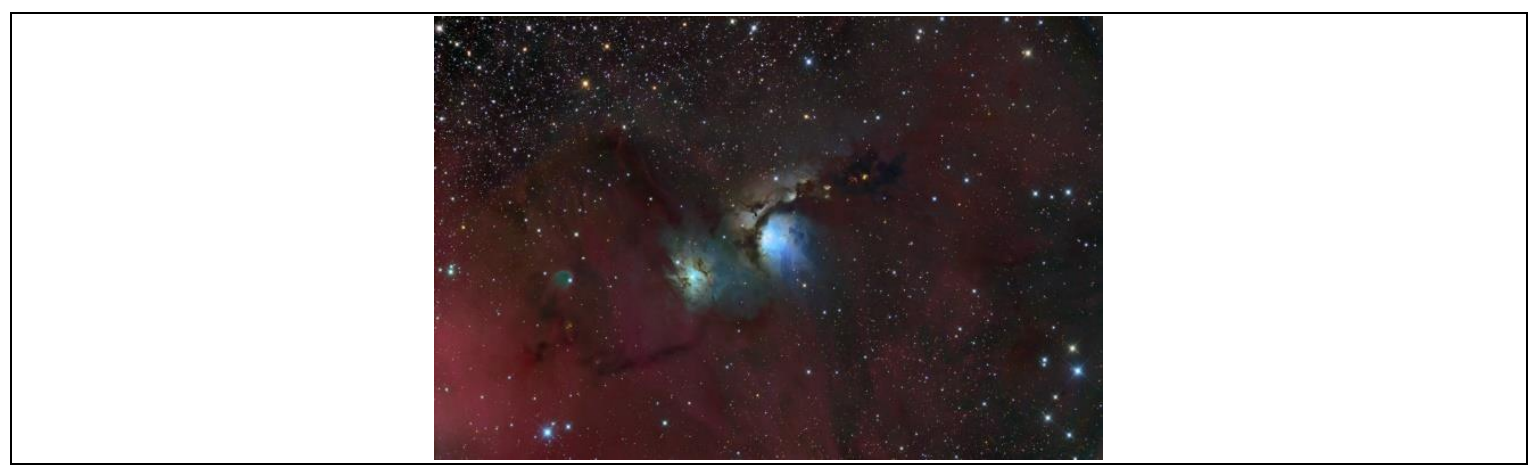

Figura 7: Nebulosa M-78 (Reflexão).

Fonte: NASA (2009).

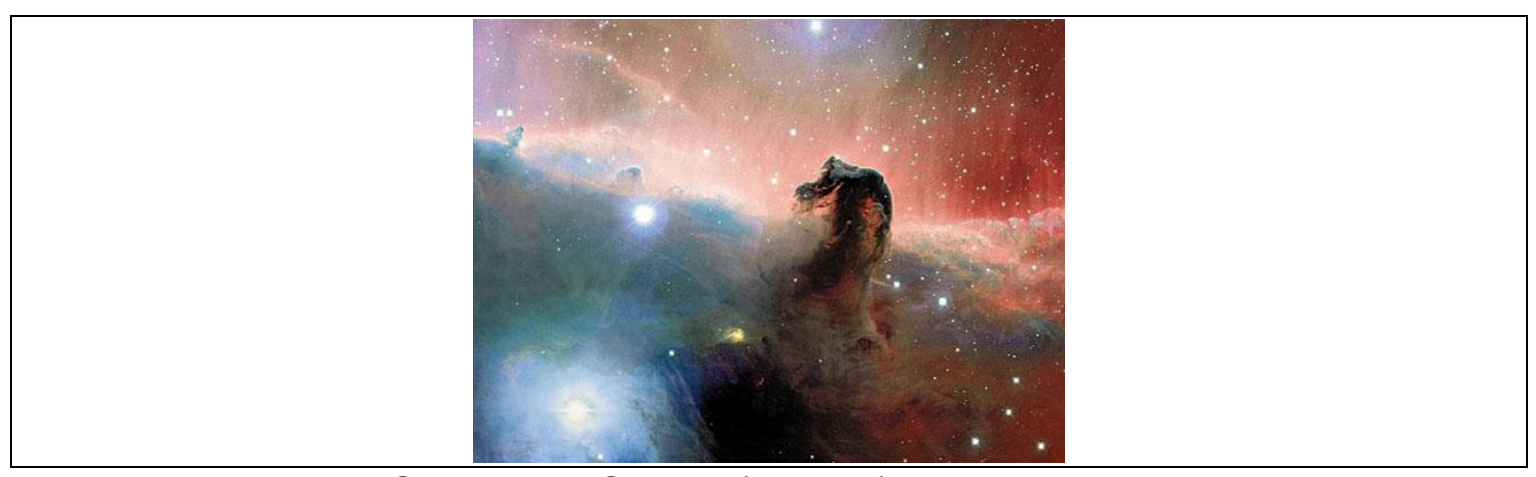

Figura 8: Nebulosa Cabeça de Cavalo (Escura), com parte brilhante da Nebulosa de Órion $(\mathrm{H}-\mathrm{II})$ ao fundo.

Fonte: NASA (2008).

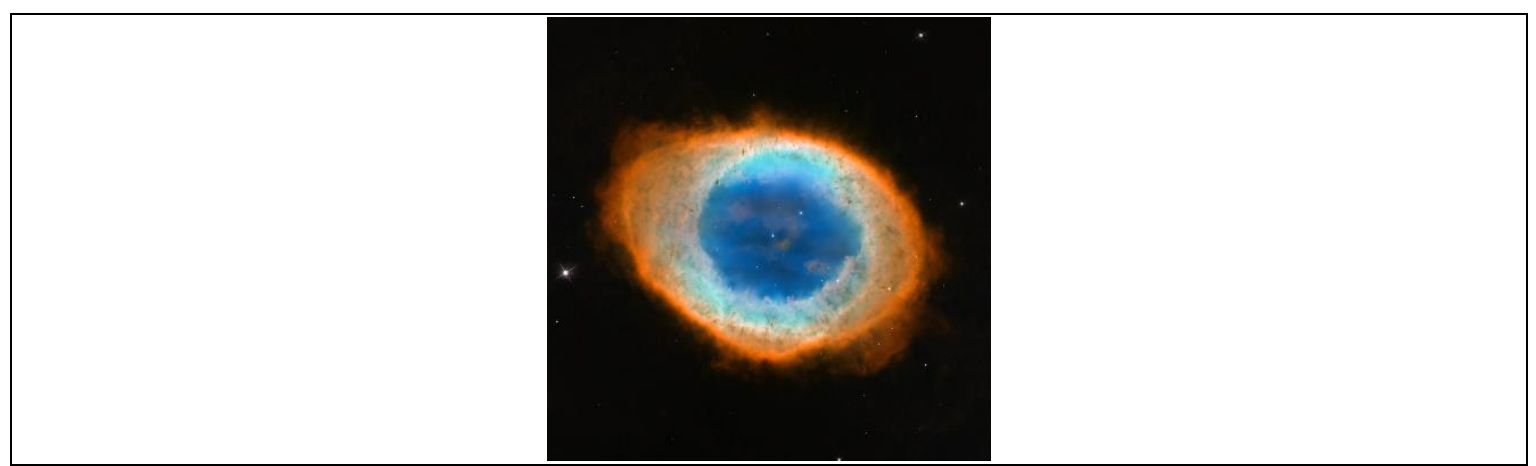

Figura 9: Nebulosa do Anel (Planetária).

Fonte: NASA (2017b). 


\subsection{Catálogos de Objetos de Céu Profundo}

Existem diversos catálogos listando os objetos de céu profundo, cada um com suas peculiaridades. Entre os mais conhecidos e utilizados, destacam-se o Catálogo Messier (M) e o New General Catalogue (NGC).

\subsubsection{Catálogo Messier}

Charles Messier (1730-1817) foi um astrônomo francês, responsável pela elaboração do primeiro catálogo de objetos de céu profundo - aglomerados, nebulosas, galáxias etc.

Apaixonado por astronomia desde a infância, iniciou sua vida profissional como auxiliar de escritório do astrônomo naval Joseph Delisle. Logo começou a progredir na carreira, de forma que passou a ter acesso ao observatório utilizado por Delisle, o que permitiu o início de suas observações (PUGH, 2012).

No fim da década de 1750, muitos astrônomos estavam em busca do Cometa Halley, a fim de comprovar (ou não) a previsão do astrônomo Edmond Halley (1656-1742) sobre a trajetória cíclica do cometa que, hoje, leva seu nome. Messier, inspirado pela busca ao cometa Halley passou, também, a rastrear e localizar diversos outros cometas.

Durante a sua "caça" aos cometas, Messier observou, em 1758, um objeto difuso no céu, mas que não se movimentava (como os cometas). Ele decidiu, então, registrar esse objeto e sua localização, a fim de evitar confusões futuras na busca por cometas. Este objeto difuso, atualmente, é conhecido por Nebulosa do Caranguejo, ou Messier 1 (M1), o primeiro objeto do Catálogo Messier (MACHHOLZ, 2002).

Entre 1758 e 1782, Messier, trabalhando em conjunto com Pierre Méchain, catalogaram 103 objetos de céu profundo. A atual versão do Catálogo Messier, entretanto, contém 110 objetos, pois os pesquisadores Helen Hogg e Owen Gingerich "redescobriram" 7 objetos, em meio às anotações de Messier e Méchain (PUGH, 2012). 


\subsubsection{O New General Catalogue (NGC) e o Index Catalogue (IC)}

De acordo com Cavin (2012), o New General Catalogue (NGC) é fruto do esforço do astrônomo John Dreyer (1852-1926). Quando este assumiu a direção do Observatório Armagh, na Irlanda do Norte, em 1882, passou a registrar diversos objetos de céu profundo, a fim de ampliar e corrigir os catálogos existentes - em especial, o Catálogo Geral de Nebulosas, publicado por John e William Herchel em 1864.

O NGC possui, originalmente, 7840 objetos registrados ${ }^{1}$ - cerca de $78 \%$ destes pertenciam ao Catálogo Geral de Nebulosas. Entretanto, cerca de 4000 destes objetos foram catalogados por Dreyer, mas foram frutos de observações de inúmeros outros astrônomos que contribuíram com a criação do NGC.

O próprio Dreyer, ao longo dos anos, continuou aprimorando e ampliando seus registros. Em 1895, ele publicou um suplemento denominado Index Catalogue (IC), adicionando 1529 objetos e corrigindo muitos registros do NGC. Em 1908, uma segunda edição do IC continha 3857 objetos, além de correções no NGC e na primeira edição do IC.

Atualmente, um projeto contínuo de revisão e ampliação do NGC/IC está em andamento - denominado Revised New General Catalogue and Index Catalogue (RNGC/IC) - e a atualização de fevereiro de 2021 já inclui 13957 objetos de céu profundo.

\footnotetext{
${ }^{1}$ Cabe destacar a significativa evolução técnica dos telescópios durante o período compreendido entre a criação do NGC e o período em que Messier registrou seus 110 objetos.
} 


\section{CAPÍTULO 2:}

\section{INICIANDO NA ASTRONOMIA}

OBSERVACIONAL

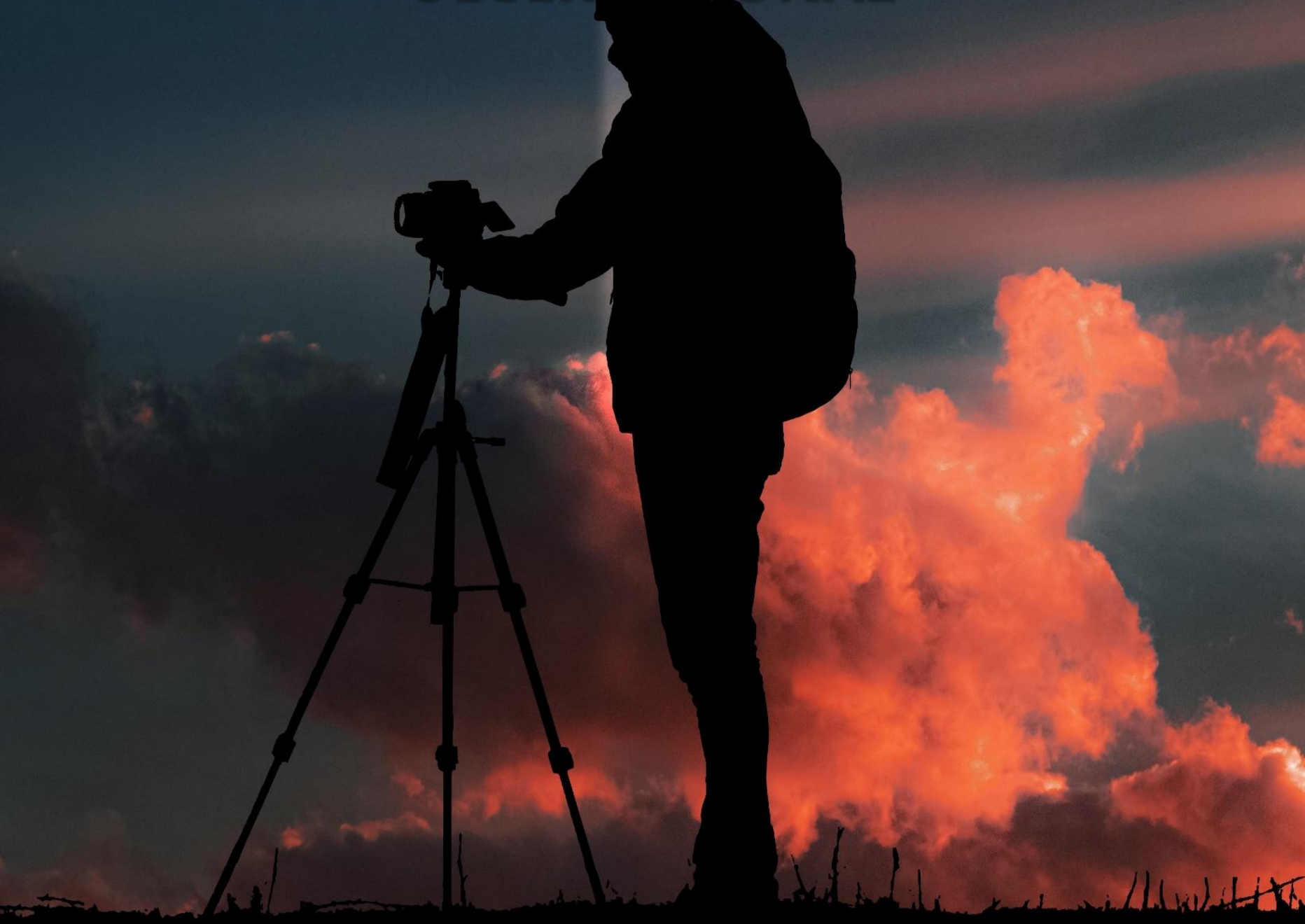




\subsection{O que é a Astronomia Observacional}

A astronomia não é uma ciência exclusivamente direcionada à academia. Nesse sentido, muitas contribuições valiosas ainda podem ser fornecidas por astrônomos amadores. A observação sistemática do céu noturno, inclusive, sequer demanda equipamentos avançados para ser uma atividade prazerosa aos amadores (claro que possuir um Meade Starlock LX600 ajudaria muito, mas querer nem sempre é poder...).

Seja com um telescópio financeiramente acessível, um bom par de binóculos ou até mesmo a olho nu, é possível observar e se maravilhar com os objetos diversos existentes em nosso universo. Como diz o professor Basílio Santiago (2021, p. 1): "A Astronomia não é uma ciência experimental, mas sim observacional".

Assim, se você ler o livro "Astronomia para Leigos" (2011), descobrirá que os astrônomos amadores contribuem de inúmeras formas com a ciência, como o monitoramento de brilho de estrelas variáveis e a descoberta de asteroides, cometas e outros corpos celestes. Há muito espaço para se aventurar na astronomia observacional!

\subsection{Instrumentos de Observação}

Uma vez que esta obra é um guia básico para iniciantes na astronomia, não cabe aqui uma explicação detalhada a respeito da natureza dos instrumentos utilizados em astronomia. Caso queira pesquisar mais, recomendamos a leitura do livro "O Céu Que Nos Envolve", de Enos Picazzio (2011), que tem um tópico específico sobre isso. Outra boa sugestão para iniciantes é o Guia llustrado Zahar: Astronomia (RIDPATH, 2014).

Nesse sentido, é sempre importante que a astronomia observacional se inicie a olho nu, para que o iniciante comece a situar as constelações no céu noturno. Nesse sentido, já é possível observar alguns objetos do Catálogo Messier sem nenhum tipo de equipamento - evidentemente, isso dependerá das condições climáticas e de poluição luminosa de sua região (aspecto esse que 
será abordado mais à frente). O Quadro 2 mostra alguns objetos Messier que podem ser observados a olho nu.

Quadro 2: Objetos do Catálogo Messier visíveis a olho nu.

\begin{tabular}{|c|c|c|c|c|c|}
\hline $\begin{array}{c}\text { Objeto } \\
\text { Messier }\end{array}$ & Constelação & $\begin{array}{c}\text { Magnitude } \\
\text { Aparente }\end{array}$ & $\begin{array}{c}\text { Objeto } \\
\text { Messier }\end{array}$ & Constelação & $\begin{array}{c}\text { Magnitude } \\
\text { Aparente }\end{array}$ \\
\hline M-2 & Aquário (Aqr) & 6,30 & M-33 & Triângulo (Tri) & 5,72 \\
\hline M-3 & Cães de Caça (CVn) & 6,20 & M-34 & Perseu (Per) & 5,20 \\
\hline M-4 & Escorpião (Sco) & 5,90 & M-35 & Gêmeos (Gem) & 5,10 \\
\hline M-5 & Serpente (Ser) & 6,65 & M-36 & Cocheiro (Aur) & 6,00 \\
\hline M-6 & Escorpião (Sco) & 4,20 & M-37 & Cocheiro (Aur) & 5,60 \\
\hline M-7 & Escorpião (Sco) & 3,30 & M-38 & Cocheiro (Aur) & 6,40 \\
\hline M-8 & Sagitário (Sgr) & 6,00 & M-39 & Cisne (Cyg) & 4,60 \\
\hline M-10 & Ofíuco (Oph) & 6,40 & M-41 & Cão Maior (CMa) & 4,50 \\
\hline M-11 & Escudo (Sct) & 6,30 & M-42 & Orion (Ori) & 4,00 \\
\hline M-12 & Ofíuco (Oph) & 7,68 & M-44 & Câncer (Cnc) & 3,10 \\
\hline M-13 & Hércules (Her) & 5,80 & M-45 & Touro (Tau) & 1,20 \\
\hline M-15 & Pégasus (Peg) & 6,30 & M-46 & Popa (Pup) & 6,10 \\
\hline M-16 & Serpente (Ser) & 6,00 & M-47 & Popa (Pup) & 4,40 \\
\hline M-17 & Sagitário (Sgr) & 6,00 & M-48 & Hidra Fêmea (Hya) & 5,80 \\
\hline M-21 & Sagitário (Sgr) & 5,90 & M-50 & Sagitário (Sgr) & 5,90 \\
\hline M-22 & Sagitário (Sgr) & 5,10 & M-52 & Cassiopéia (Cas) & 6,90 \\
\hline M-23 & Sagitário (Sgr) & 5,50 & M-55 & Sagitário (Sgr) & 7,42 \\
\hline M-24 & Sagitário (Sgr) & 4,60 & M-67 & Câncer (Cnc) & 6,90 \\
\hline M-25 & Sagitário (Sgr) & 4,60 & M-81 & Ursa Maior (UMa) & 6,94 \\
\hline M-27 & Raposa (Vul) & 7,40 & M-92 & Hércules (Her) & 6,40 \\
\hline M-31 & Andrômeda (And) & 3,44 & M-93 & Popa (Pup) & 6,20 \\
\hline
\end{tabular}

Fonte: adaptado de Harrington (2018).

Como tais condições não estão disponíveis à maioria dos aspirantes à astrônomo amador, é recomendado a aquisição de algum instrumento para ampliar sua capacidade de observação. Com um bom binóculo, a tarefa de observar os objetos Messier do Quadro 2 ficará muito mais fácil.

Após exaustiva pesquisa em sites, redes sociais, blogs, entrevistas com especialistas etc., foi possível constatar que 99\% das fontes investigadas recomendam que o primeiro instrumento astronômico a ser adquirido seja um bom binóculo. Por quê?

Em primeiro lugar, binóculos são consideravelmente mais baratos que telescópios. É possível, inclusive, importar bons binóculos por valores inferiores aos limites impostos pela Receita Federal. Dependendo do momento econômico vivenciado no nosso país, a importação pode se tornar uma alternativa atraente, desde que se observe com atenção a credibilidade das lojas pesquisadas. 
Em segundo lugar, o campo de visão de um binóculo é consideravelmente maior do que o da maioria dos telescópios, permitindo explorar áreas maiores do céu a cada observação (RIDPATH, 2014).

Além disso, nem todas as pessoas que iniciam os estudos astronômicos prosseguem com a atividade observacional, de forma sistemática. Assim, o investimento em um instrumento astronômico pode se tornar um custo irrecuperável, dada a dificuldade que o indivíduo pode enfrentar ao tentar vender seu equipamento.

Portanto, de maneira consensual, recomenda-se a aquisição de um bom binóculo para o início das atividades. Mas, afinal de contas, o que seria um "bom binóculo"?

\subsubsection{Binóculos}

Existe um ditado popular que diz "não adianta uma roubar uma tonelada de ouro para carregar somente 20 quilos nas costas". Este ditado pode ser aplicado na escolha dos binóculos: não adianta comprar binóculos ultra potentes, mas que sejam muito pesados.

Binóculos são equipamentos que geralmente são utilizados sem qualquer tipo de suporte, demandando um esforço físico considerável para manter uma observação razoavelmente estabilizada. E não há exagero nessa afirmativa: apesar da maioria dos binóculos aparentar leveza, não há prazer algum em sustentar (com estabilidade) um binóculo $25 \times 100$, como será demonstrado a seguir.

Existem binóculos dos mais variados tipos de tamanho e especificações técnicas, como mostra a Figura 10. 


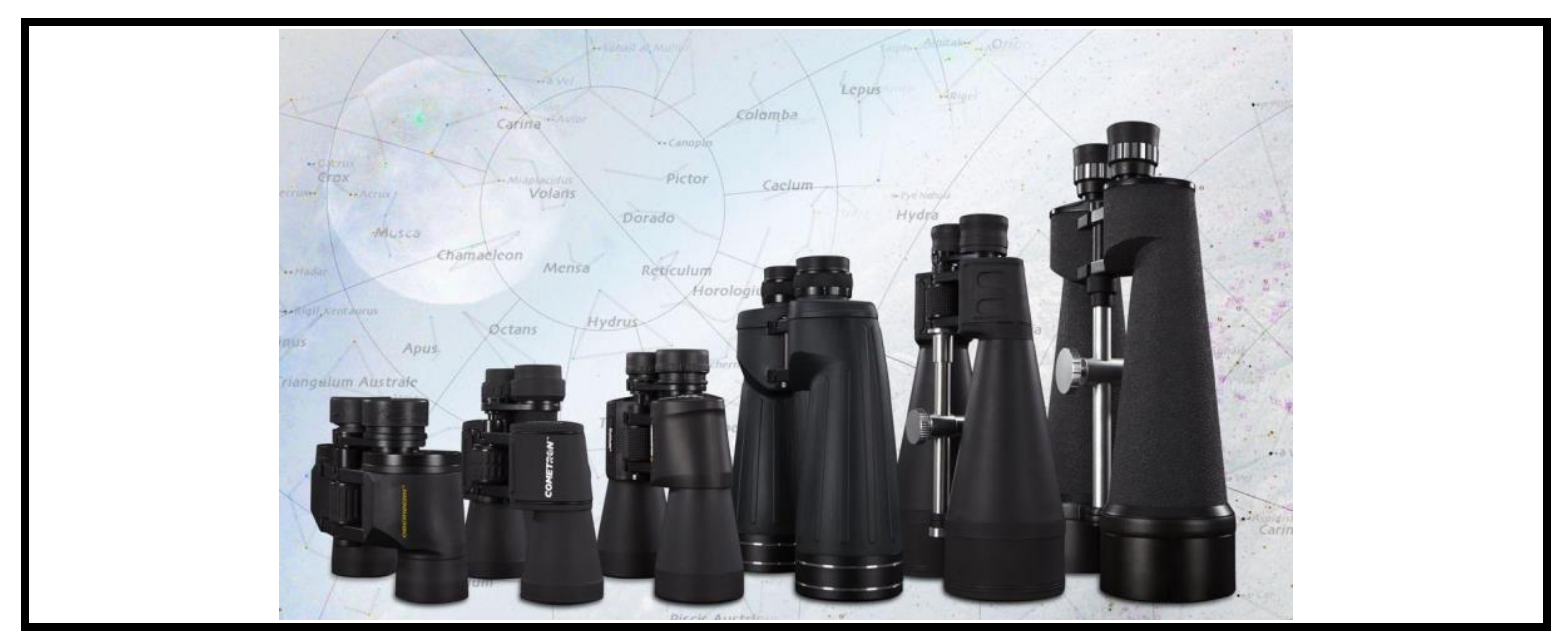

Figura 10: Binóculos de diferentes capacidades e tamanhos.

Fonte: Brody (2018).

E o que seria um binóculo 25×100? Em geral, binóculos são classificados em função de sua capacidade de ampliação e em função da largura de suas lentes (que representa a abertura para a entrada de luz). O binóculo do exemplo (25x100), portanto, tem a capacidade de ampliar em 25 vezes a visão (em relação ao olho nu) e possui lentes de 100mm (que permitem a entrada de uma quantidade "satisfatória" de luz). Um binóculo 25x100 é, portanto, um instrumento astronômico com desempenho superior, inclusive, ao de alguns telescópios para iniciantes.

Entretanto, este não é um modelo indicado para iniciantes pois, além de se tratar de um modelo de preço pouco convidativo, deve-se considerar a questão do manuseio do instrumento. Um binóculo 25x100 tem peso aproximado de $4 \mathrm{~kg}$, tornando-o completamente inviável sua utilização sem um tripé de apoio, como mostra a Figura 11.

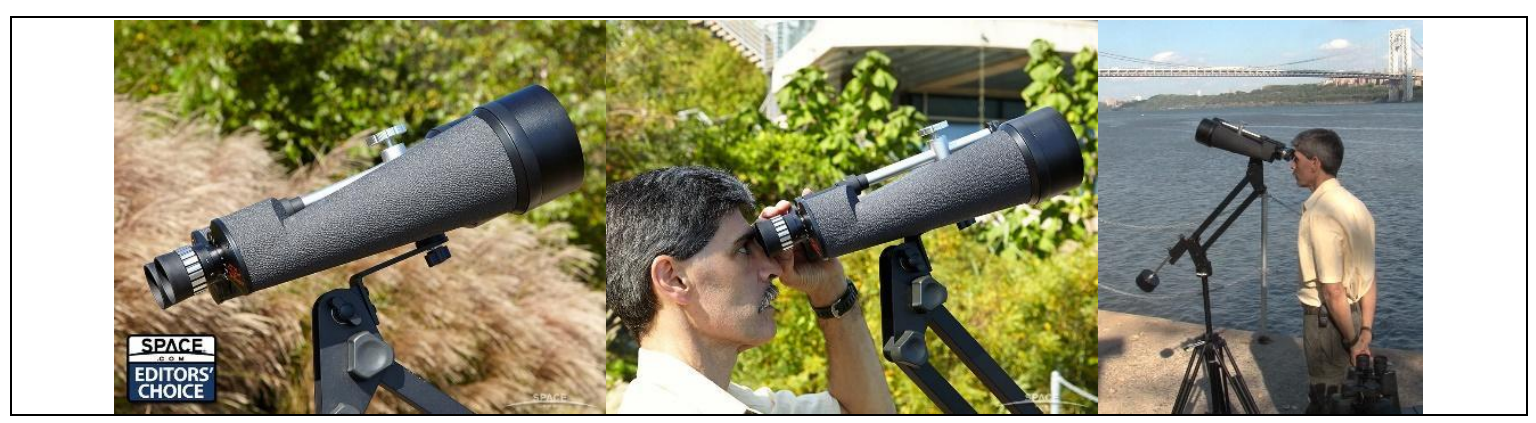

Figura 11: Uso de binóculo 25×100 com tripé.

Fonte: adaptado de Brody (2018). 
Nesse sentido, a recomendação é que o "primeiro binóculo" da jornada astronômica seja um modelo $7 \times 50$ ou 10×50, por apresentarem boa relação custo-benefício-peso. Binóculos com abertura de $50 \mathrm{~mm}$ já fornecem um incremento significativo na observação astronômica. Kerste (2018) aponta que o ganho fornecido por um binóculo de $50 \mathrm{~mm}$, em relação ao olho nu, é similar ao ganho fornecido quando se passa de um binóculo de $50 \mathrm{~mm}$ para um telescópio de 14" (que custa muitos milhares de reais).

Além disso, Crato (2000) e Carreira (2004) acrescentam as seguintes recomendações na hora de adquirir um binóculo para astronomia:

- Procurar binóculos com lentes "coated", "multi-coated" ou "fully multicoated", pois estas permitirão maior entrada de luz no instrumento;

- Priorizar binóculos com prismas Bak4, que são de melhor qualidade na reflexão da luz;

- Evitar binóculos que possuam "zoom". Geralmente são de má qualidade e, além disso, possuem um número maior de peças móveis, facilitando o desalinhamento do sistema ótico;

- Priorize binóculos com distância do olho à ocular ("eye-relief") mínima de $10 \mathrm{~mm}$ (para quem não precisa de óculos) e de $20 \mathrm{~mm}$ (para quem utiliza óculos);

Aviso Importante: Instrumentos astronômicos de qualidade NÃO são vendidos na "Papelaria X" ou na "Loja de Informática Y". Em geral, estes estabelecimentos comercializam produtos de má qualidade de fabricação, apenas para observações de paisagens, não sendo recomendados para astronomia. Tenha muito cuidado na hora de procurar o melhor preço de binóculos ou telescópios, e se atenha às principais marcas do mercado (Celestron, Meade, Orion, Nikon etc.). Esta é uma daquelas situações nas quais "o barato sai caro", então pesquise com atenção.

Muita coisa pode ser feita somente com binóculos. Alguns entusiastas, como Gary Seronik (2012), já se aventuraram a observar todos os objetos do Catálogo Messier apenas com a utilização de binóculos (modelos variados). Então a recomendação é aproveitar os binóculos o máximo possível para aprimorar as técnicas e, somente em um momento futuro, pensar no telescópio. 


\subsubsection{Telescópios}

Como dito anteriormente, não serão abordadas questões ligadas ao tipo de telescópio e/ou tipo de imagem gerada por cada tipo de telescópio, pois já existe uma vasta literatura sobre tais assuntos.

$\mathrm{Na}$ prática, a aquisição de um telescópio demanda um considerável investimento financeiro, que pode ser agravado em função de variações cambiais. Isto porque existem pouquíssimos fabricantes de telescópios de qualidade no Brasil e, ainda assim, estes ficam à mercê das variações cambiais na hora de importar insumos.

Considerando que muitos anseios consumistas dos iniciantes na astronomia são ceifados pelas restrições orçamentárias, este guia se baseará nestas restrições para organizar dicas sobre telescópios. Nesse sentido, uma boa recomendação para iniciantes seria um telescópio refletor, com abertura entre $114 \mathrm{~mm}$ e $150 \mathrm{~mm}$, de razão focal preferencialmente inferior a f/6 e de montagem altazimutal.

A escolha por um telescópio refletor se dá por questões financeiras: telescópios refratores ou catadióptricos com a mesma abertura de um refletor são significativamente mais caros.

Já no que tange à abertura do telescópio, percebe-se que uma maior abertura significa maior capacidade de observar objetos mais sutis no céu profundo. Entretanto, o preço dos telescópios aumenta quase que exponencialmente em relação à sua abertura. Em função disso, telescópios com abertura maior que $150 \mathrm{~mm}$ costumam ser financeiramente inviáveis para muitos iniciantes - exceto entusiastas da fabricação de telescópios ${ }^{2}$. No mesmo sentido, a observação de objetos de céu profundo demanda telescópios com baixa razão focal, pois estes permitem maior entrada de luz.

Por fim, a montagem altazimutal foi indicada em função de sua facilidade de manuseio por iniciantes. Um dos tipos mais conhecidos de montagem altazimutal é a montagem dobsoniana.

Algumas dicas adicionais em relação aos telescópios:

\footnotetext{
2 Existem inúmeros grupos em redes sociais e páginas na internet que fornecem orientações bem didáticas a respeito da fabricação de telescópios refletores com base dobsoniana.
} 
- Fuja de telescópios "de livraria", com "capacidade de até 600x de aumento" ou coisa parecida. Este tipo de equipamento, além de ter qualidade de fabricação duvidosa, é inadequado para observações astronômicas - se for o caso, mantenha-se somente com os binóculos;

- Fuja de marcas desconhecidas. As principais marcas do mercado Meade, Celestron, Sky-Watcher e Orion - não são referências à toa. São marcas que oferecem produtos de qualidade, e astronomia requer qualidade de observação;

- Tenha sempre em mente o equilíbrio entre a capacidade do telescópio e sua facilidade de transporte, pois muitos astrônomos precisam transportar seu equipamento para áreas com menor poluição luminosa, de forma que não adianta investir uma fortuna em um "mini James Webb" e não conseguir carregá-lo sempre que quiser;

- Ter uma base motorizada no telescópio ajuda muito, mas esse tipo de "mimo" eleva significativamente o valor do telescópio, e não é nem um pouco indispensável;

- Caso decida adquirir um telescópio "Made in Brazil", temos bons fabricantes com preços bem acessíveis. Alguns exemplos de bons fabricantes nacionais são Sandro Colletti, Sebastião Salgado Filho e Telescópios Matão.

A Figura 12 mostra alguns modelos de telescópios que se enquadram na recomendação deste guia.

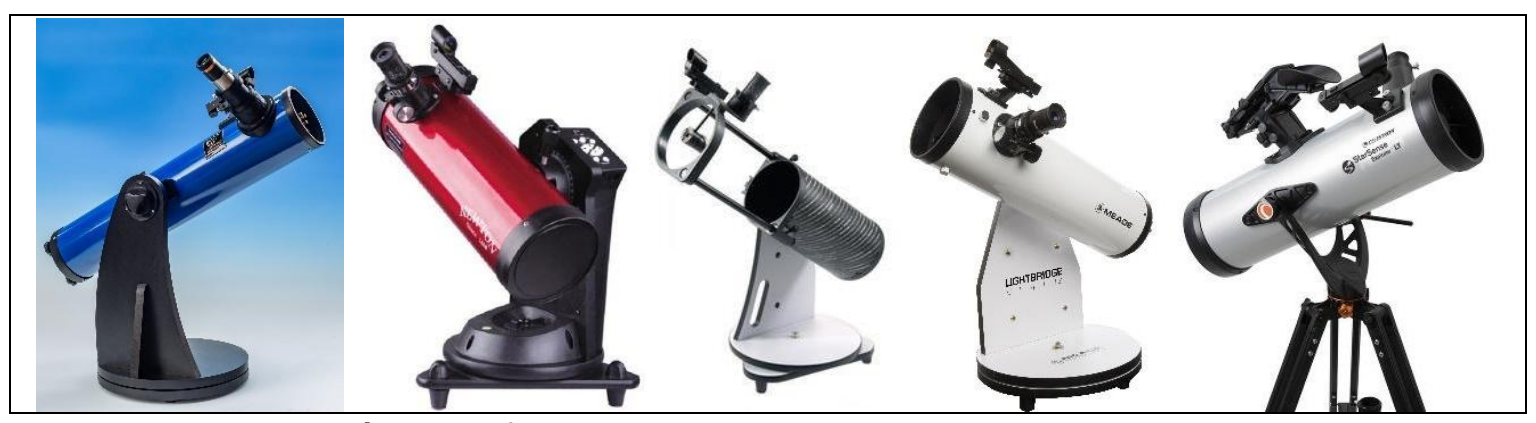

Figura 12: Telescópios refletores newtonianos, de montagem altazimutal e com abertura entre $114 \mathrm{~mm}$ e $115 \mathrm{~mm}$.

Fonte: Coletti (2020), Astroshop (2021), Meade Instruments (2021) e Celestron (2021). 
Em condições observacionais adequadas, é praticamente garantida a observação de todos os objetos do Catálogo Messier com algum destes equipamentos (STOYAN et al., 2008). Um iniciante na astronomia pode utilizar um destes modelos por anos, antes de efetivamente surgir a necessidade de evoluir para modelos maiores (e mais caros).

\subsection{Softwares e Astronomia Observacional}

Uma vez definido o equipamento a ser utilizado, é hora de ir para o campo. E geralmente, aqui ocorre o primeiro "empacamento" do iniciante da astronomia: como localizar objetos de céu profundo?

Há algum tempo atrás, a melhor forma de localizar os objetos do Catálogo Messier era por meio da consulta a cartas celestes, que são mapas com a localização de objetos celestes diversos, de acordo com a época do ano e a latitude desejada.

Atualmente, muitas associações de astronomia amadora ainda incentivam a consulta às cartas celestes. Apesar do aspecto vintage inegavelmente relacionado às cartas celestes, este incentivo ainda tem como finalidade estimular, nos iniciantes, a capacidade de localização e identificação de objetos celestes.

A seguir, a Figura 13 e Figura 14 exibem exemplos de cartas celestes, com a localização de alguns objetos Messier. 


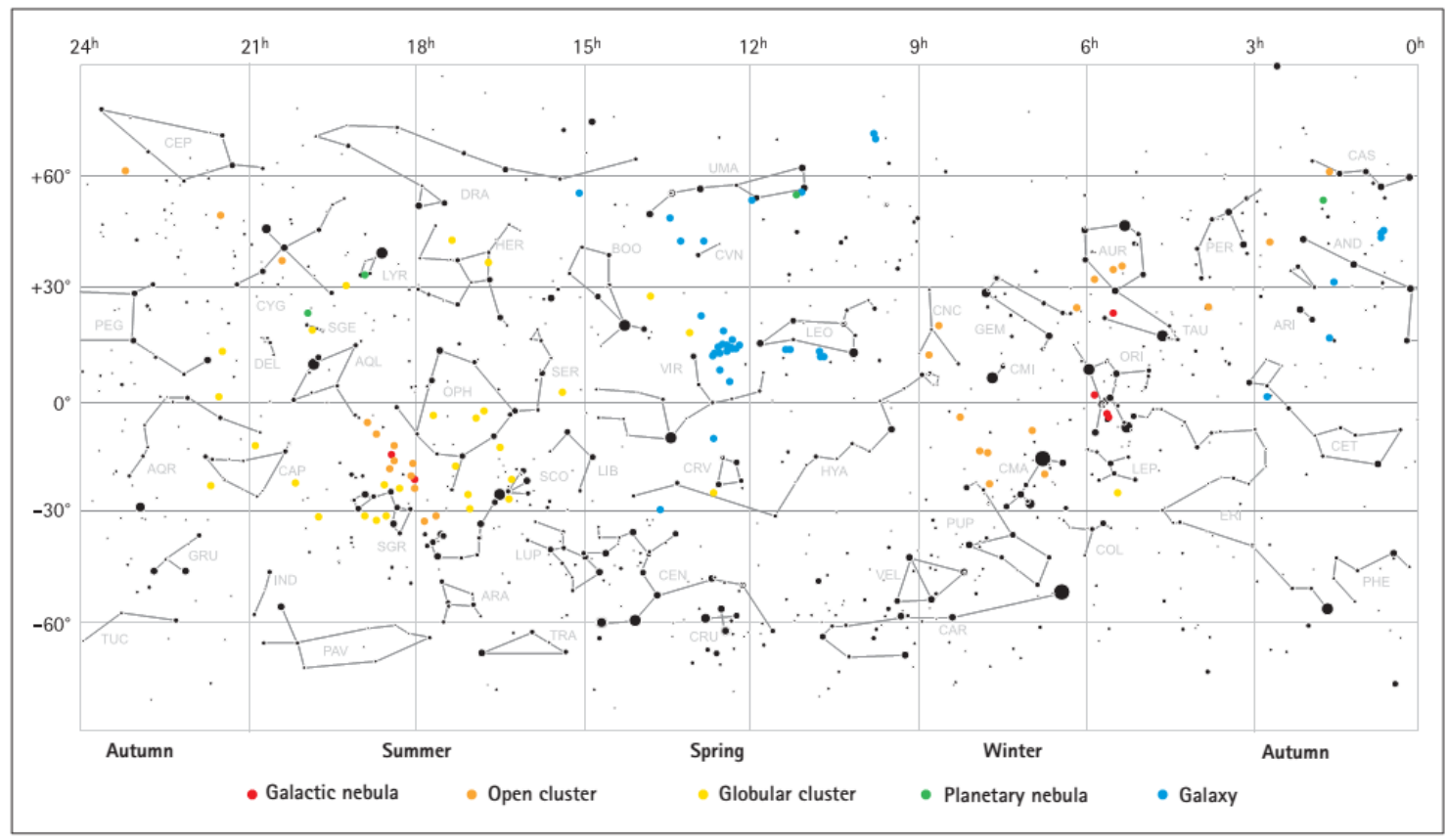

Figura 13: Distribuição dos objetos Messier no céu.

Fonte: Stoyan et al. (2008).

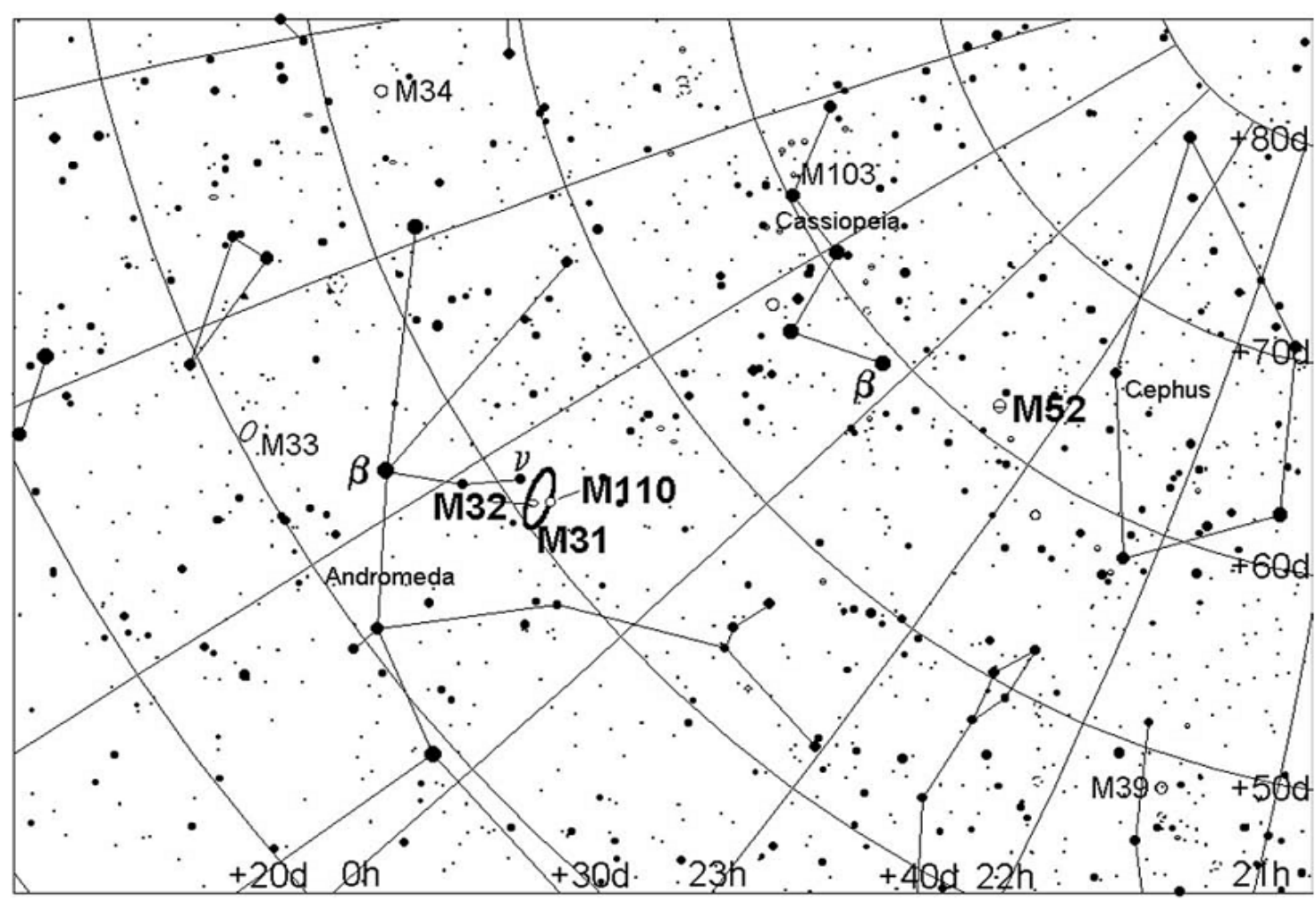

Figura 14: Localização dos objetos M31, M32, M34, M34, M39, M103 e M110. Fonte: Machholz (2002).

Entretanto, a intensa revolução computacional das últimas décadas fez com que muitos astrônomos iniciantes passassem a ter acesso a computadores, smartphones e tablets que facilitam significativamente a "caça" aos objetos de céu profundo. 
Nesse sentido, separamos alguns softwares que podem ajudar nas observações astronômicas:

\subsubsection{Stellarium (PC, iOS e Android)}

Não há como falar de softwares astronômicos sem mencionar o Stellarium. Trata-se de um planetário de código aberto que indica a posição dos corpos celestes, de acordo com a localização e o tempo informado pelo usuário (ZOTTI; WOLF, 2020). Além disso, possui um robusto banco de informações sobre os corpos celestes, permitindo a projeção de diversos cenários noturnos, bem como a simulação da observação com diversos telescópios e oculares. A título de exemplo, a Figura 15 mostra como estava o céu de Santa Cruz Cabrália, Bahia, na noite de 22 de abril de 1500. Para efeitos comparativos, a Figura 16 mostra o céu no mesmo local, em 22 de abril de 2021.

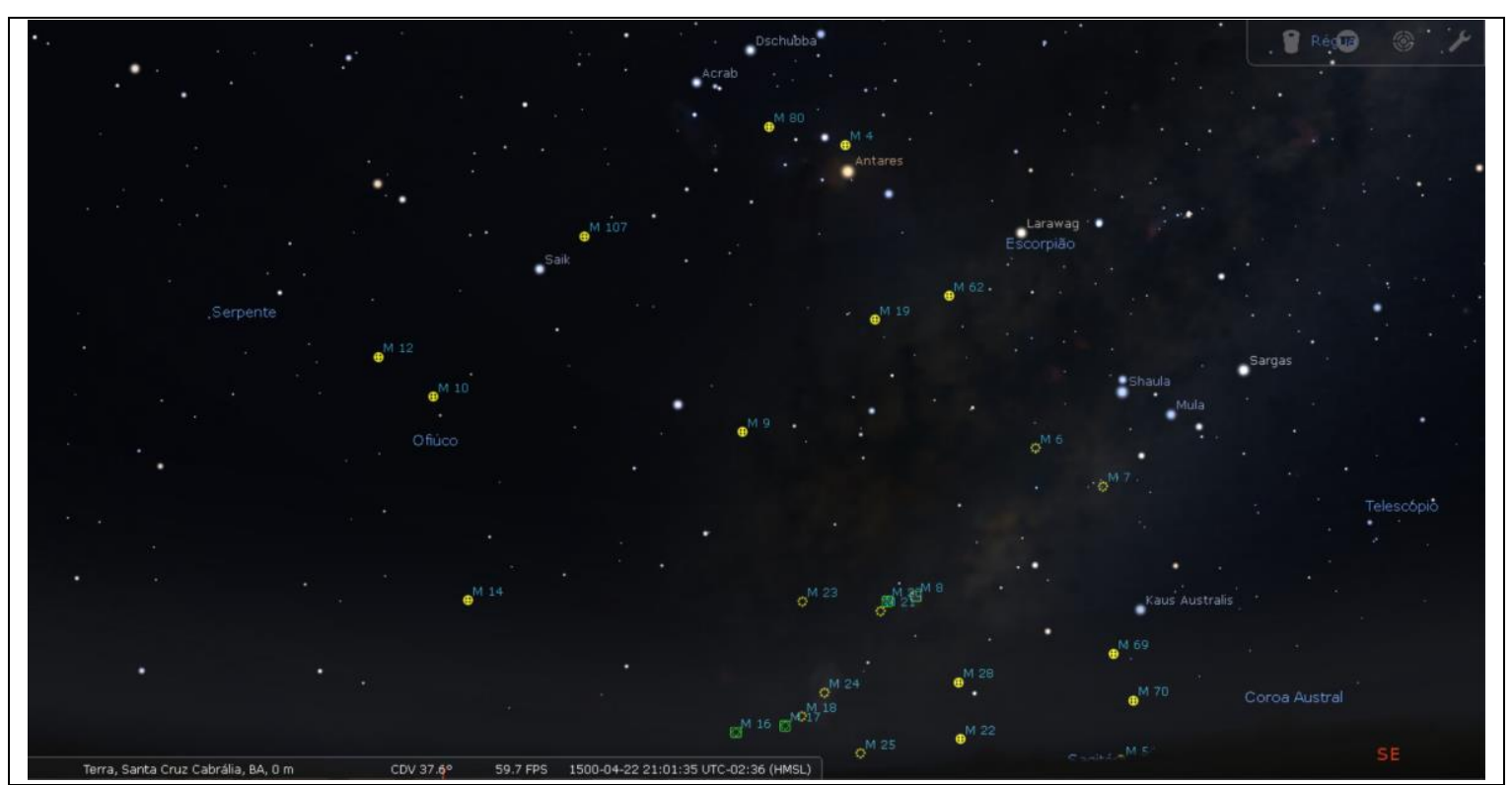

Figura 15: Projeção do céu de Santa Cruz Cabrália, Bahia, em 22 de abril de 1500.

Fonte: elaborada pelos autores. 


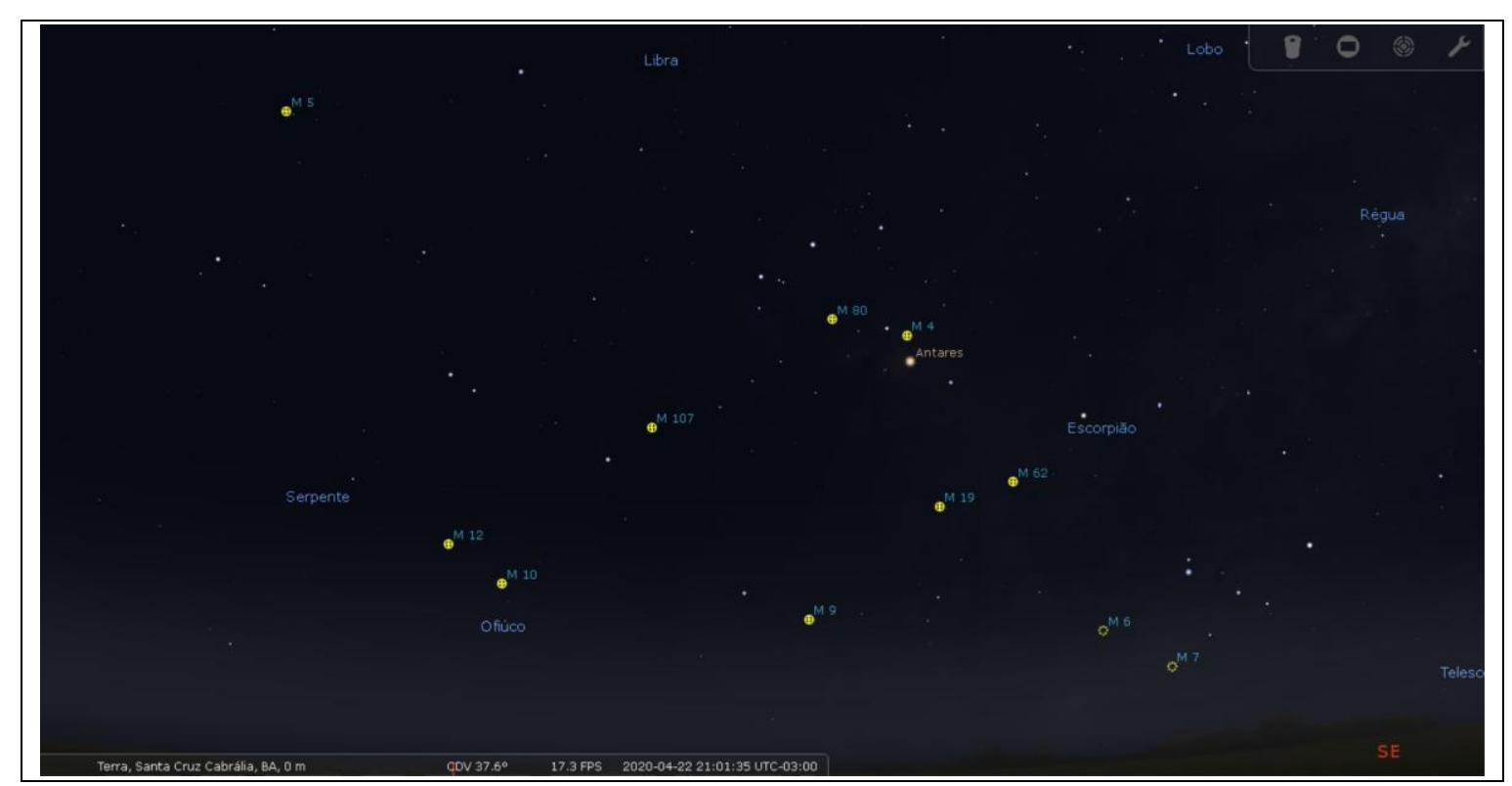

Figura 16: Projeção do céu de Santa Cruz Cabrália, Bahia, em 22 de abril de 2021.

Fonte: elaborada pelos autores.

O Stellarium foi, originalmente, lançado em versões gratuitas para Windows, Mac OS X e Linux, além de uma versão web. Recentemente, os criadores do Stellarium decidiram elaborar uma versão mobile. Contudo, o Stellarium Mobile, em sua versão gratuita, não fornece acesso aos objetos de céu profundo. A versão paga do referido software, Stellarium Mobile Plus, está sendo comercializada atualmente por um valor "não muito convidativo" para iniciantes.

Ainda assim, o Stellarium é o software mais utilizado e difundido na comunidade astronômica amadora, pela robustez do banco de dados, simplicidade de uso e pela gratuidade nas versões desktop. Clique aqui para acessar o site do Stellarium para desktop.

\subsubsection{Cartes du Ciel (PC)}

Também gratuito, o Cartes du Ciel tem versões disponíveis para Windows, Mac OS X e Linux. Ele se apresenta como uma boa alternativa ao Stellarium, apesar de não possuir o refinamento gráfico e as ricas imagens dos objetos celestes que seu concorrente. Como ponto positivo, o Cartes du Ciel, assim 
como o Stellarium, permite sua utilização para controlar telescópios motorizados (Go-To). A Figura 17 a seguir mostra a interface do Cartes du Ciel.

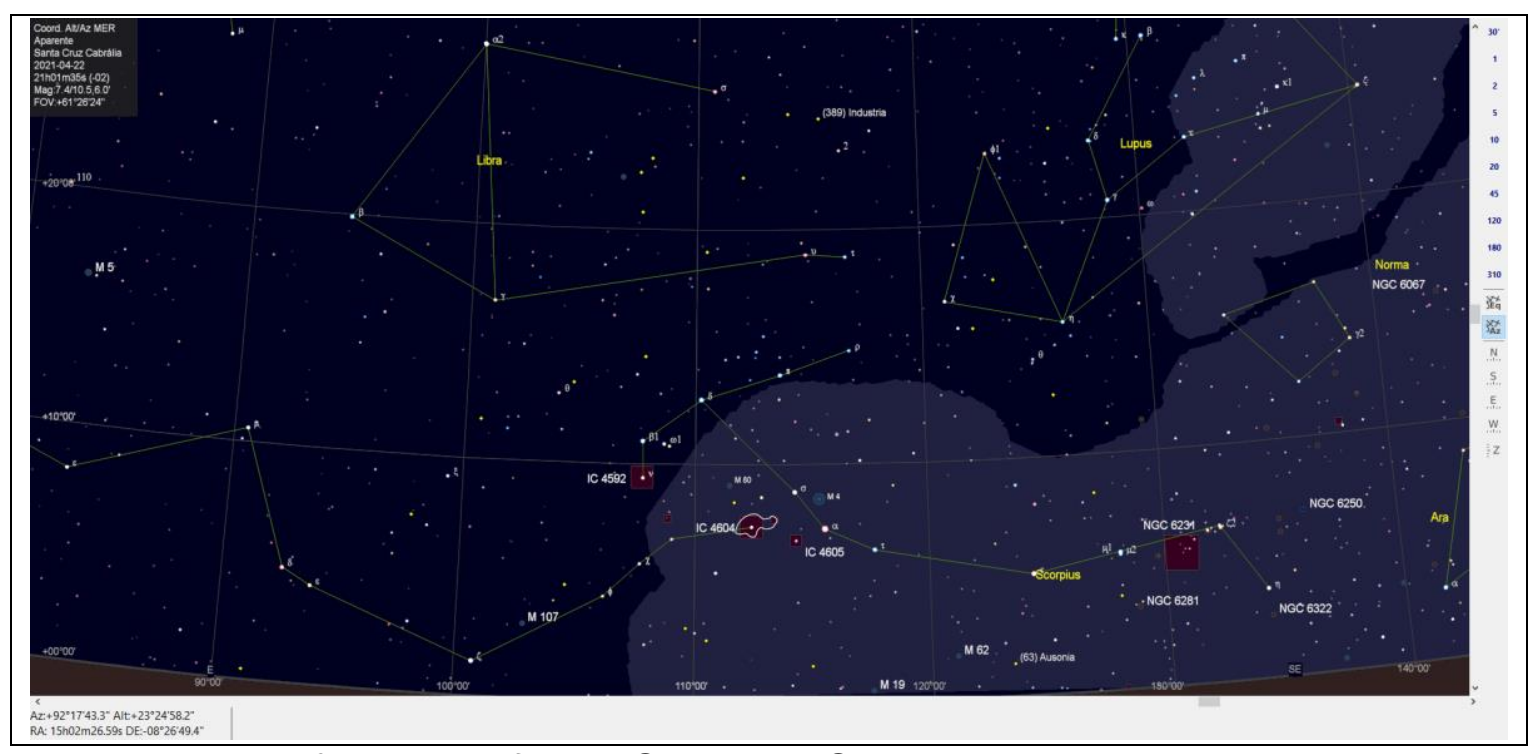

Figura 17: Interface do software Cartas du Ciel.

Fonte: elaborada pelos autores.

Clique aqui para acessar o site do Cartas du Ciel.

\subsubsection{StarWalk 2 (Android, iOS)}

Trata-se de um aplicativo com aspecto visual muito chamativo, com inúmeros recursos para auxiliar o iniciante em astronomia observacional a localizar estrelas, constelações, planetas, satélites, asteroides, cometas etc.

O StarWalk 2 é um aplicativo gratuito. Contudo, infelizmente, para acessar os objetos de céu profundo é necessário comprar um pacote dentro do aplicativo. Por outro lado, o valor deste pacote é cerca de $10 \%$ do valor cobrado pelo Stellarium Mobile, sendo que ele oferece muito mais que $10 \%$ dos recursos oferecidos pelo seu concorrente. A Figura 18 mostra a interface gráfica do StarWalk 2. 


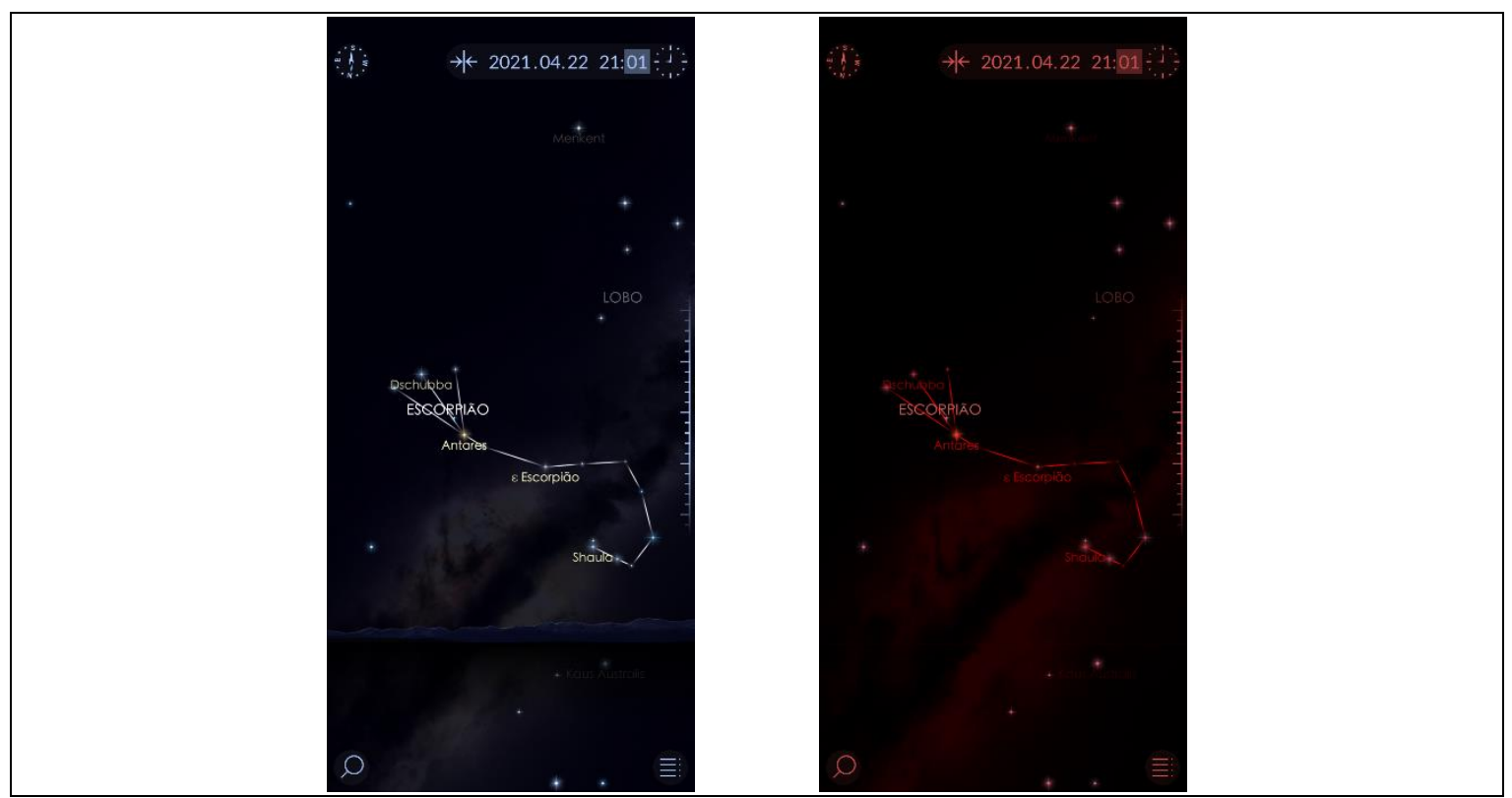

Figura 18: Interface do aplicativo StarWalk2, nos modos normal e noturno. Fonte: elaborada pelos autores.

\subsubsection{SkyMap (Android)}

O SkyMap é um aplicativo gratuito - totalmente gratuito - que permite localizar diversos corpos celestes de acordo com a localização e tempo fornecidos pelo usuário. A Figura 19 mostra a interface gráfica do Sky Map.

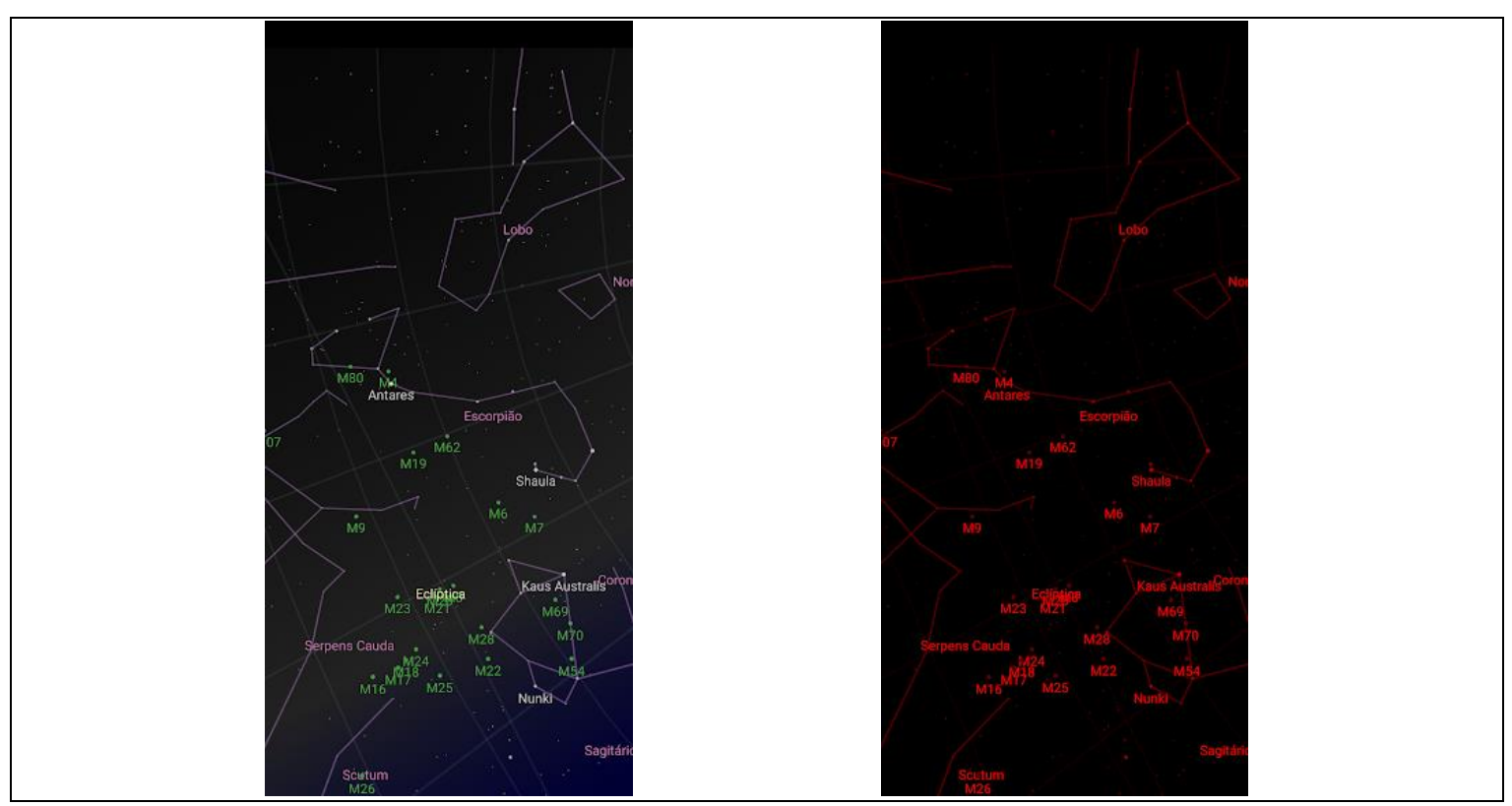

Figura 19: Interface do aplicativo SkyMap, nos modos normal e noturno. Fonte: elaborada pelos autores. 
Trata-se de uma versão mobile do Google Sky, e já foi considerado o melhor aplicativo para observação do céu há alguns anos. Contudo, apesar de atualmente não ser considerado o que há de melhor em observação astronômica, lembre-se do totalmente gratuito, destacado no início da descrição.

\subsubsection{SkySafari (iOS e Android)}

Outra opção para auxiliar as observações astronômicas é o Sky Safari, aplicativo gratuito para Android e pago para iOS. Com menu intuitivo e fácil navegação, trata-se de uma opção a ser considerada seriamente, caso queira fugir das opções pagas mencionadas anteriormente. A Figura 20 a seguir mostra a interface gráfica do SkySafari.

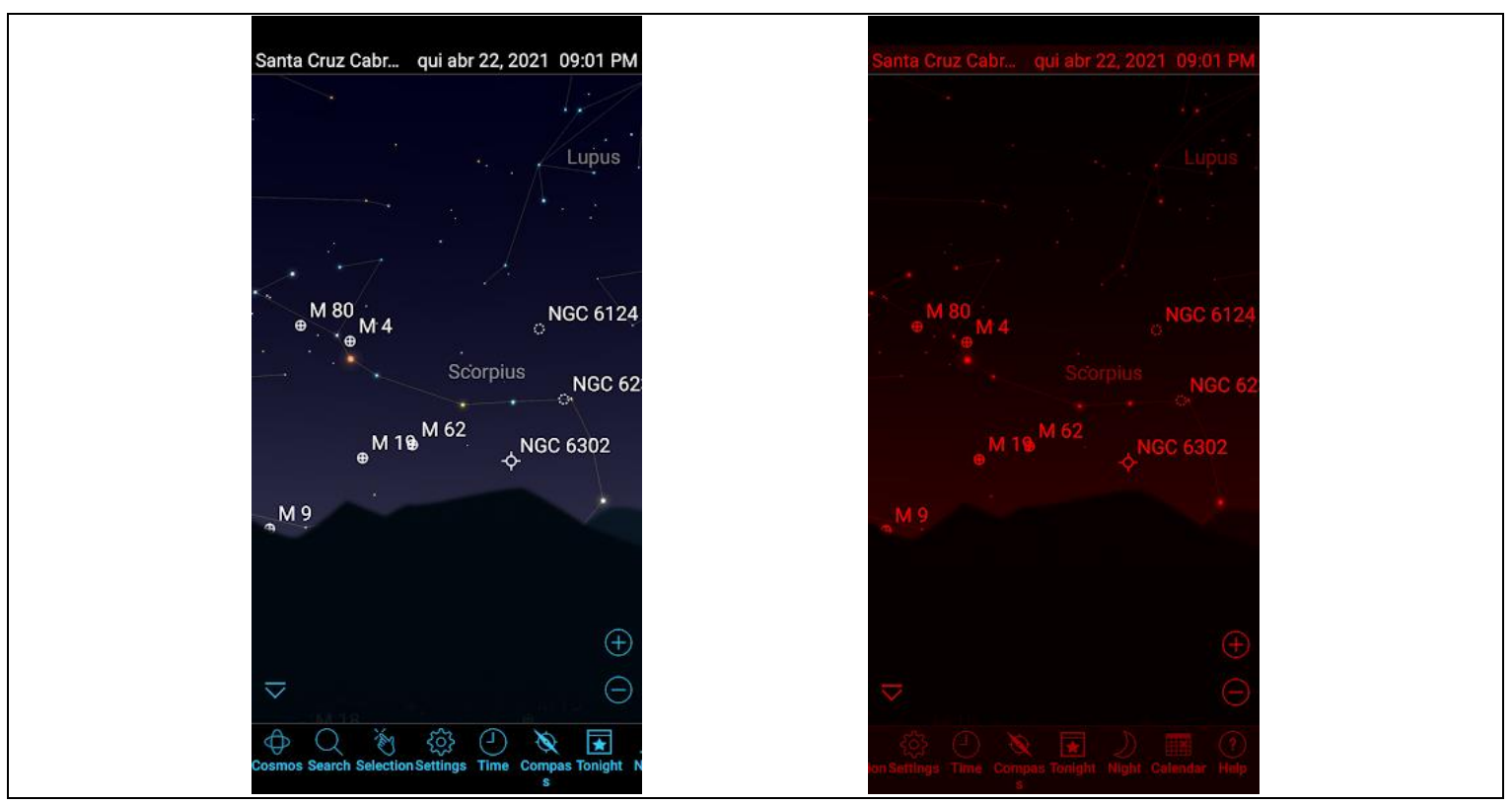

Figura 20: Interface do aplicativo SkySafari, nos modos normal e noturno. Fonte: elaborada pelos autores.

\subsubsection{MESSMARA (PC)}

O MESSMARA é um software gratuito projetado para astrônomos que desejam fazer uma "Maratona Messier" (observar todos os objetos Messier em uma única noite). Mesmo não sendo possível realizar uma maratona completa 
no Brasil em uma única noite, esse software se torna indispensável para planejar suas observações, uma vez que ele informa quantos objetos Messier estarão visíveis (de acordo com a data e a localização desejada), bem como quais não estarão vivíveis, conforme Figura 21 a seguir.

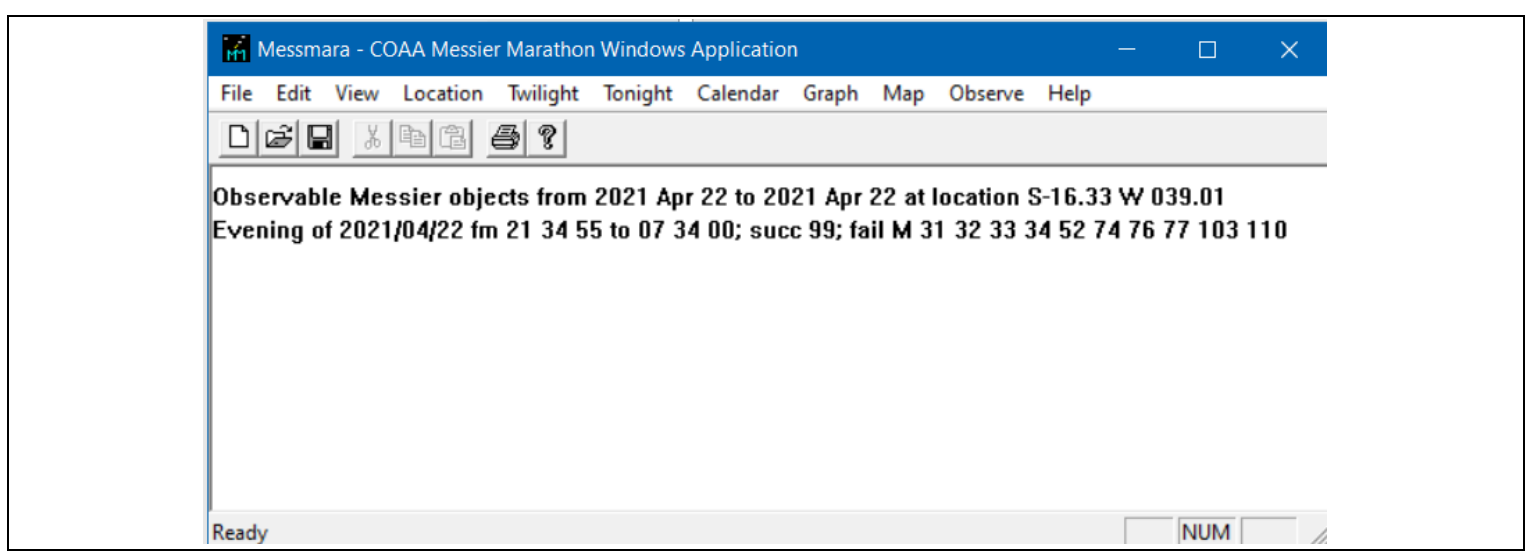

Figura 21: Interface gráfica do software MESSMARA

Fonte: elaborada pelos autores.

Evidentemente, os auxílios eletrônicos auxiliam muito, mas não são indispensáveis à astronomia observacional. Muito se pode fazer com uma prancheta, alguns mapas celestes e uma lanterna avermelhada, de forma que a restrição orçamentária não pode ser considerada um limitador da atividade astronômica amadora. Não se pode dizer o mesmo, infelizmente, a respeito da poluição luminosa, que é o assunto do próximo tópico e que pode comprometer significativamente a astronomia observacional.

\subsection{Poluição Luminosa, Escala de Bortle e Escala de Transparência}

A Poluição Luminosa (PL), segundo Oliveira e Langhi (2011), se refere ao fenômeno provocado pelo excesso ou direcionamento inadequado de iluminação artificial. Trata-se de um tema de fundamental importância para a astronomia, posto que a PL é uma ameaça significativa para o exercício da astronomia observacional. Os autores ainda apontam pesquisas anteriores que indicam que, 
em função do elevado nível de poluição luminosa no planeta, um observador fora da Terra poderia até mesmo considerar que o mesmo possui iluminação própria.

Gargaglioni (2009) aponta que existem três tipos de poluição luminosa:

- Brilho no céu: brilho alaranjado, visto acima das cidades, e causado pelo direcionamento adequado das luzes;

- Ofuscamento: luz direta nos olhos, que ofusca a visão;

- Luz intrusa: luz que atravessa diferentes ambientes, eliminando a escuridão absoluta necessária à observação astronômica.

Como consequência direta da PL, muitas regiões do planeta já não se encontram em condições adequadas para o exercício da astronomia observacional, pois muitos objetos celestes deixam de ser visíveis diante da poluição luminosa.

Nesse sentido, Slotegraaf (2008) indicou, para diferentes níveis de poluição luminosa, qual o limite mínimo de magnitude que permitiria uma observação a olho nu, conforme o Quadro 3 a seguir.

Quadro 3: Influência da poluição luminosa na visibilidade de objetos celestes

\begin{tabular}{|c|c|}
\hline Nível de Poluição Luminosa & Magnitude Mínima Visível \\
\hline Mínima & Aproximadamente 6,6 \\
\hline Muito Pequena & 5,6 a 6,5 \\
\hline Leve & 4,6 a 5,5 \\
\hline Moderada & 3,1 a 4,5 \\
\hline Severa & Acima de 3,0 \\
\hline
\end{tabular}

Fonte: adaptado de Slotegraaf (2008).

Visando auxiliar os astrônomos a identificar o nível de escuridão do campo de observação, Bortle (2006) elaborou uma escala de nove pontos, descritos no Quadro 4 a seguir. 
Quadro 4: Escala de Bortle de escuridão do céu.

\begin{tabular}{|c|c|c|}
\hline Escala & Nome & Descrição \\
\hline 1 & Céu excelente & $\begin{array}{c}\text { Perfeita visibilidade da luz zodiacal. A olho nu, é possível } \\
\text { visualizar objetos de magnitude entre } 7 \text { e } 8 .\end{array}$ \\
\hline 2 & Tipicamente escuro & $\begin{array}{c}\text { Evidências iniciais de luminescência atmosférica. A Via } \\
\text { Láctea ainda é completamente visível a olho nu, bem como } \\
\text { objetos de magnitude entre } 7 \text { e } 7,5 \text {. }\end{array}$ \\
\hline 3 & Céu rural & $\begin{array}{l}\text { Evidências iniciais de poluição luminosa. Ainda pode se ver a } \\
\text { Via Láctea, bem como objetos com magnitude entre } 6,5 \text { e } 7 \text {. }\end{array}$ \\
\hline 4 & $\begin{array}{l}\text { Transição rural- } \\
\text { suburbano }\end{array}$ & $\begin{array}{l}\text { Surgimento de focos de poluição luminosa. A Via Láctea já } \\
\text { não se apresenta de forma estruturada. Objetos com } \\
\text { magnitude entre } 6,0 \text { e } 6,5 \text { ainda visíveis a olho nu. }\end{array}$ \\
\hline 5 & Céu suburbano & $\begin{array}{c}\text { A Via Láctea está praticamente invisível. O olho nu consegue } \\
\text { visualizar objetos de magnitude entre } 5,5 \text { e } 6 \text {. }\end{array}$ \\
\hline 6 & $\begin{array}{l}\text { Céu suburbano } \\
\text { iluminado }\end{array}$ & $\begin{array}{l}\text { Não é possível visualizar a luz zodiacal. A Via Láctea só } \\
\text { pode ser vista no zênite. Somente objetos de magnitude } \\
\text { inferior a 5,5 são visíveis. }\end{array}$ \\
\hline 7 & $\begin{array}{l}\text { Transição } \\
\text { suburbano-urbano }\end{array}$ & $\begin{array}{l}\text { Poluição luminosa em todas as direções. A Via Láctea esta } \\
\text { praticamente invisível. Somente objetos com magnitude } \\
\text { inferior a } 5 \text { são visíveis a olho nu, com esforço. }\end{array}$ \\
\hline 8 & Céu urbano & $\begin{array}{l}\text { É possível ler no escuro. Muitas constelações já não são } \\
\text { visíveis, posto que somente objetos com magnitude inferior a } \\
4,5 \text { são visíveis a olho nu. }\end{array}$ \\
\hline 9 & $\begin{array}{l}\text { Céu de centro- } \\
\text { urbano }\end{array}$ & $\begin{array}{c}\text { Céu completamente iluminado. A maioria das constelações } \\
\text { já não são visíveis, bem como qualquer objeto com } \\
\text { magnitude superior a } 4 .\end{array}$ \\
\hline
\end{tabular}

Fonte: Bortle (2006).

A Figura 12 a seguir ilustra a Escala de Bortle.

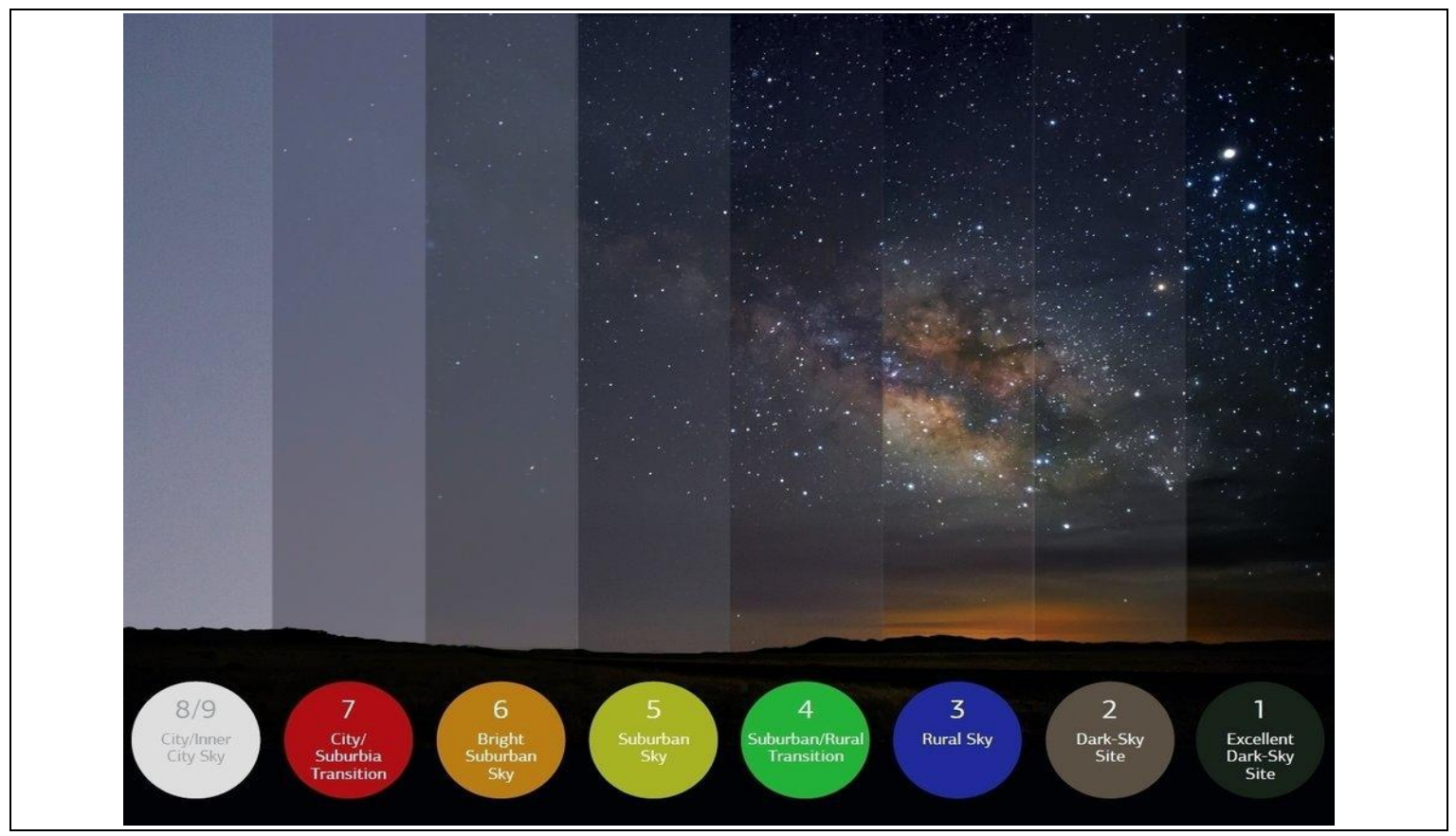

Figura 12: Escala de Bortle

Fonte: King (2018). 
Além da Escala de Bortle, outra escala muito utilizada mede a quantidade de nuvens no céu, por meio da Escala de Transparência disposta no Quadro 5 a seguir:

Quadro 5: Escala de Transparência

\begin{tabular}{|c|c|c|}
\hline Escala & Condição & Descrição \\
\hline 0 & Completamente nublado & Não há estrelas visíveis \\
\hline 1 & Muito pobre & Nuvens cobrindo a maior parte do céu \\
\hline 2 & Pobre & Nuvens irregulares ou névoa pesada \\
\hline 3 & Pouco claro & Cirrus ou névoa moderada \\
\hline 5 & Parcialmente claro & Ligeira névoa \\
\hline 6 & Limpo & $\begin{array}{c}\text { Ausência de nuvens, pouca interferência do dimpo } \\
\text { brilho de cidades e pouquíssima poluição } \\
\text { luminosa }\end{array}$ \\
\hline 7 & Extremamente limpo & $\begin{array}{c}\text { Ausência de nuvens, interferência mínima do } \\
\text { brilho de cidades. Céu escuro. }\end{array}$ \\
\hline
\end{tabular}

Fonte: Tellescópio.com (2014). 


\section{CAPÍTULO 3:}

\section{DICAS DE OBSERVAÇÃO}

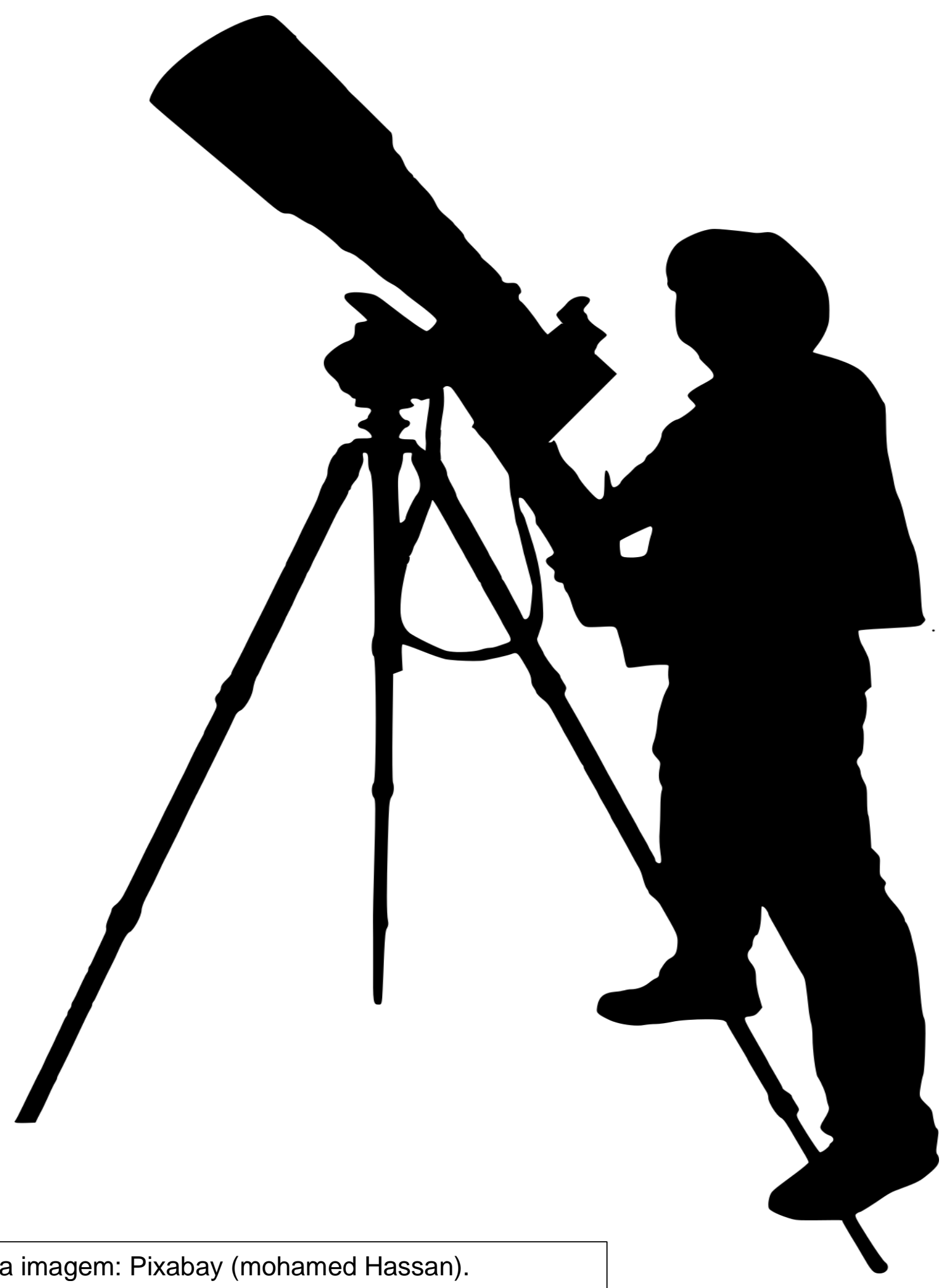


No intuito de auxiliar os iniciantes em sua jornada astronômica, seguem algumas dicas:

\subsection{Localização e Conforto}

\section{Dica 01: escolha bem o local de observação}

Procure um local com a menor poluição luminosa possível. Evidentemente, nem todos possuem condições de se deslocar para a zona rural, fugindo da poluição das cidades. Nesses casos é importantíssimo procurar um local com a maior escuridão possível. O site Light Pollution Map é de grande ajuda nesse sentido, ao fornecer um mapa global de poluição luminosa, como mostra o exemplo da Figura 22. Utilize-o para planejar adequadamente seu campo de observação.

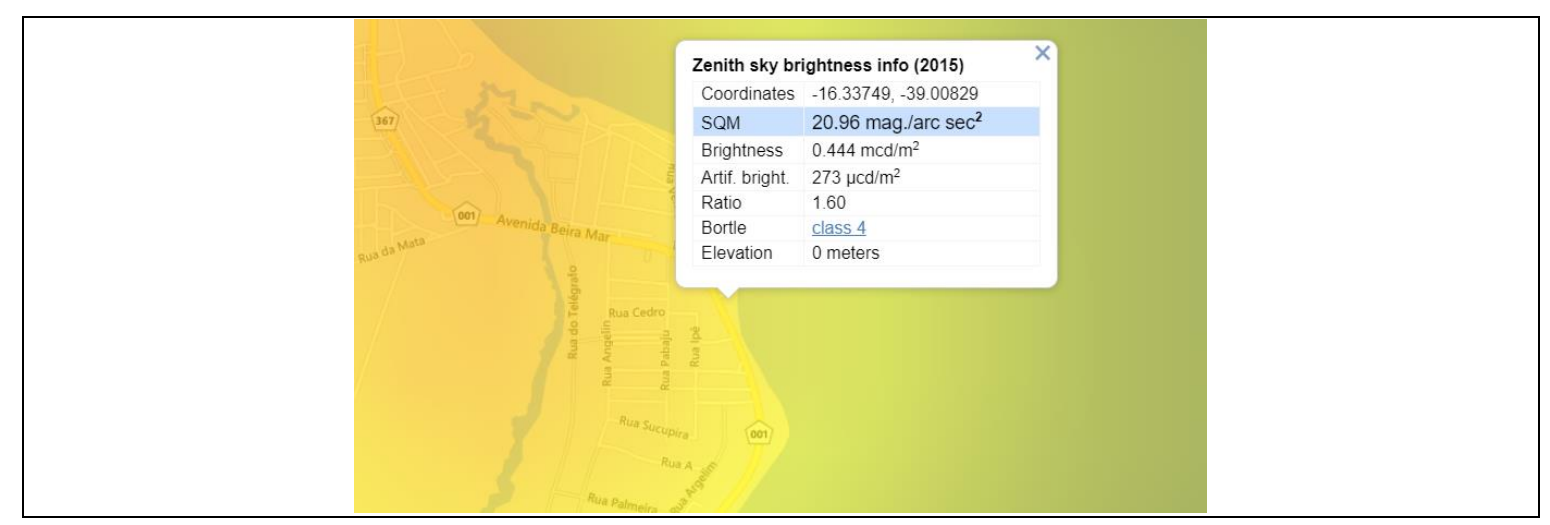

Figura 22: Interface gráfica do site Light Pollution Map.

Fonte: Light Pollution Map (2021).

\section{Dica 02: mantenha uma boa postura}

A observação de objetos de céu profundo demanda uma busca por diversas áreas do céu. Nesse sentido, é importante que seu instrumento ótico seja adequado e compatível a essas movimentações, bem como o restante de sua estrutura física (cadeira, mesa etc.). Além disso, é fundamental manter uma boa postura durante as observações (ao contrário do exemplo da Figura 23), bem como cuidar bem de sua coluna cervical e de sua coluna lombar, por meio de exercícios de alongamentos antes, durante e após a atividade astronômica observacional. 


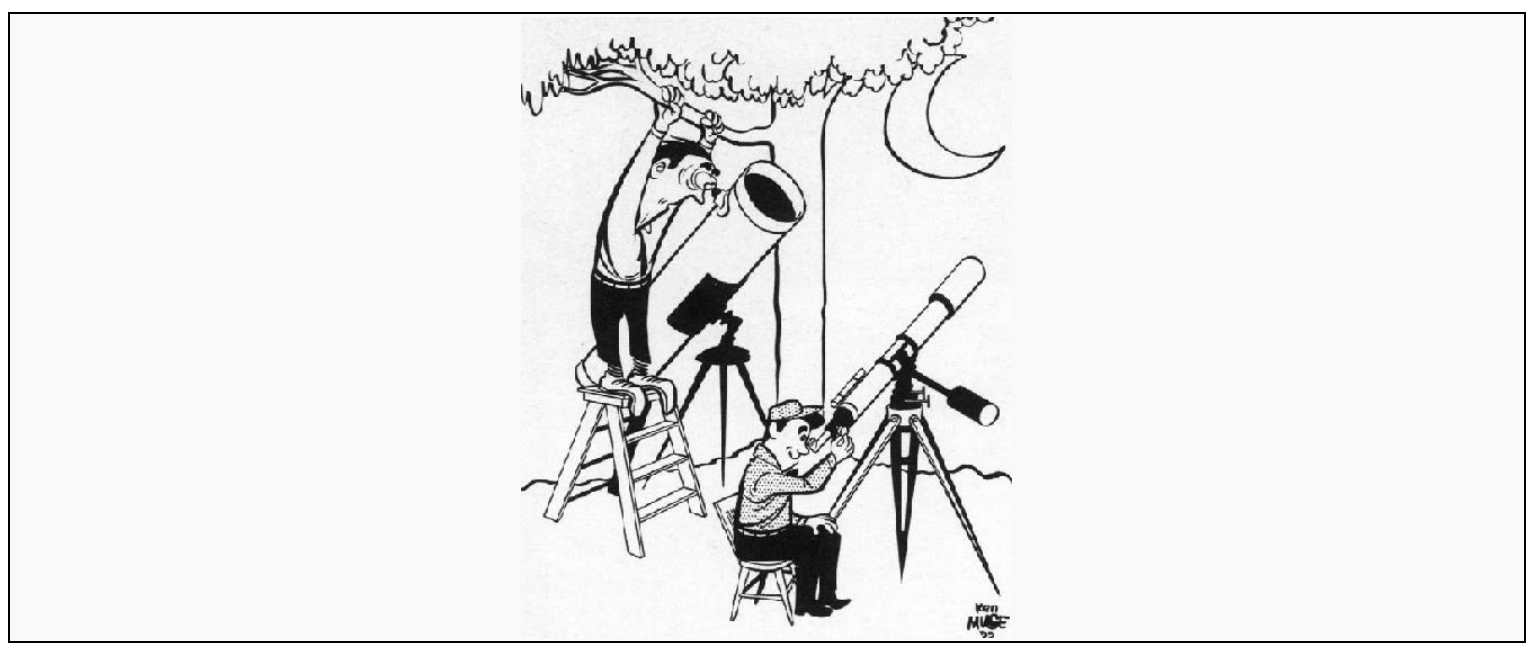

Figura 23: Exemplo de postura inadequada.

Fonte: Company Seven (2021).

\subsection{Planejamento das Observações}

\section{Dica 03: analise previamente as condições climáticas}

Antes de mais nada, tenha certeza de que conseguirá observar alguma coisa durante à noite. Nesse sentido, é fundamental verificar a previsão do tempo, não só para verificar se o céu estará limpo, mas também para o observador se adequar às temperaturas que enfrentará durante as observações. Além disso, é importante compatibilizar suas noites de observações com as fases da Lua (a observação de objetos de céu profundo é significativamente prejudicada pela magnitude da Lua Cheia, por exemplo).

\section{Dica 04: escolha previamente o que deseja observar}

Uma vez que nem todos os objetos desejados estão disponíveis para observação a qualquer noite do ano, é necessário otimizar o tempo gasto com as observações (priorizando mais a apreciação do objeto do que a procura em si). Softwares como o Stellarium e o MESSMARA conseguem fornecer uma excelente orientação a respeito dos objetos Messier que poderá observar em uma determinada noite. 


\section{Dica 05: evite deslocamentos desnecessários}

Planeje adequadamente a lista de materiais que necessitará durante suas observações. Não estamos falando somente de seus equipamentos, mas também de mantimentos e alguns materiais "reserva" (como pilhas extras, lápis extras etc.). Além disso, todos os equipamentos que utilizam pilhas ou baterias devem estar totalmente carregados, a fim de evitar imprevistos (A Dica 09 fala sobre isso, também).

\subsection{Equipamentos e Tecnologia}

\section{Dica 06: Aprenda sobre seu equipamento}

Ajuste suas observações às especificações técnicas do seu equipamento. Com um telescópio "de papelaria" ninguém conseguirá ver a Galáxia do Sombrero, por exemplo. Nesse sentido, a calculadora do site Telescópios (2021) poderá Ihe ser muito útil, ao indicar a magnitude limite de seu equipamento. Além disso, é importante que você saiba a orientação da visão de sua ocular, a fim de compatibilizar sua observação com o mapa celeste de referência.

\section{Dica 07: Utilize uma buscadora}

Buscadoras ópticas são de grande ajuda na hora de localizar objetos de céu profundo, por proporcionarem um campo de visão maior que o telescópio, com menor ampliação.

\section{Dica 08: Utilize luzes vermelhas}

Em meio à escuridão, nossa pupila se dilata para permitir a entrada de mais luz. É por isso que, depois de aproximadamente 30 minutos no escuro, conseguimos enxergar muito melhor. Entretanto, a cada vez que uma luz é acesa perto do observador, a pupila se contrai novamente e a observação é prejudicada. Para isso, recomenda-se que, se o uso de luzes se fizer necessário, 
que sejam utilizadas luzes vermelhas, pois a pupila não se contrai diante delas. $\mathrm{Na}$ falta de uma lanterna especificamente vermelha, improvise cobrindo sua lanterna (ou a lanterna do celular) com papel celofane vermelho. O uso de aplicativos de qualquer natureza no campo de observação deve ser feito no "modo noturno", a fim de reduzir o impacto da iluminação sobre os olhos.

\section{Dica 09: Não confie cegamente na tecnologia. Confie na "Lei de Murphy"}

Mesmo que levem em consideração a Dica 05, é bom saber que imprevistos acontecem. Então, esse conselho é mais direcionado para quem utiliza o máximo de tecnologia possível (tablets, smartphones, notebooks, telescópios motorizados etc.): Os equipamentos eletrônicos, inevitavelmente, irão lhe deixar na mão, em alguma noite. Nesse sentido, é fundamental ter um kit "astronomia à moda antiga" para essas ocasiões: cartas celestes impressas, prancheta, lápis, lanternas etc. Parece um conselho "bobo", mas muitos astrônomos amadores jovens não sabem navegar no céu profundo sem o uso do Stellarium, por exemplo.

\section{Dica 10: Utilize um gravador}

Essa dica é útil para quem quer ganhar tempo durante os registros observacionais: utilize um gravador de áudio (ou algum gravador no celular) para registrar suas descrições e notas observacionais. Com isso, você ganha tempo durante a noite e faz as transcrições das gravações (para o relatório de registro) em outro momento.

\subsection{Técnicas de Observação}

\section{Dica 11: Star Hopping: usando e abusando das estrelas}

Os softwares facilitaram - e muito - a vida de quem gosta de localizar objetos de céu profundo. Contudo, caso não possua um telescópio motorizado e 
devidamente alinhado a um software como o Stellarium, você precisará localizar os objetos de céu profundo "manualmente". Segundo Basey (2018), o "Star Hopping" é o ato de "saltar estrelas", partindo de estrelas facilmente localizáveis e formando padrões geográficos até chegar aos desejados objetos de céu profundo. A seguir serão reproduzidos alguns exemplos de "saltos nas estrelas" e de criação de padrões geográficos que facilitam a localização dos objetos de céu profundo:

\section{Exemplo 1: M-51}

Neste exemplo, citado por Basey (2018), M-51 situa-se na constelação de Cães de Caça (CVn), e pode ser localizado a partir de uma brilhante estrela de referência (Alkaid, com magnitude 1.85). Após localizar Alkaid, é possível mentalizar um triângulo formado por Alkaid, 24CVn e M-51, permitindo que M-51 seja encontrado e devidamente registrado, como mostra a Figura 24 a seguir.

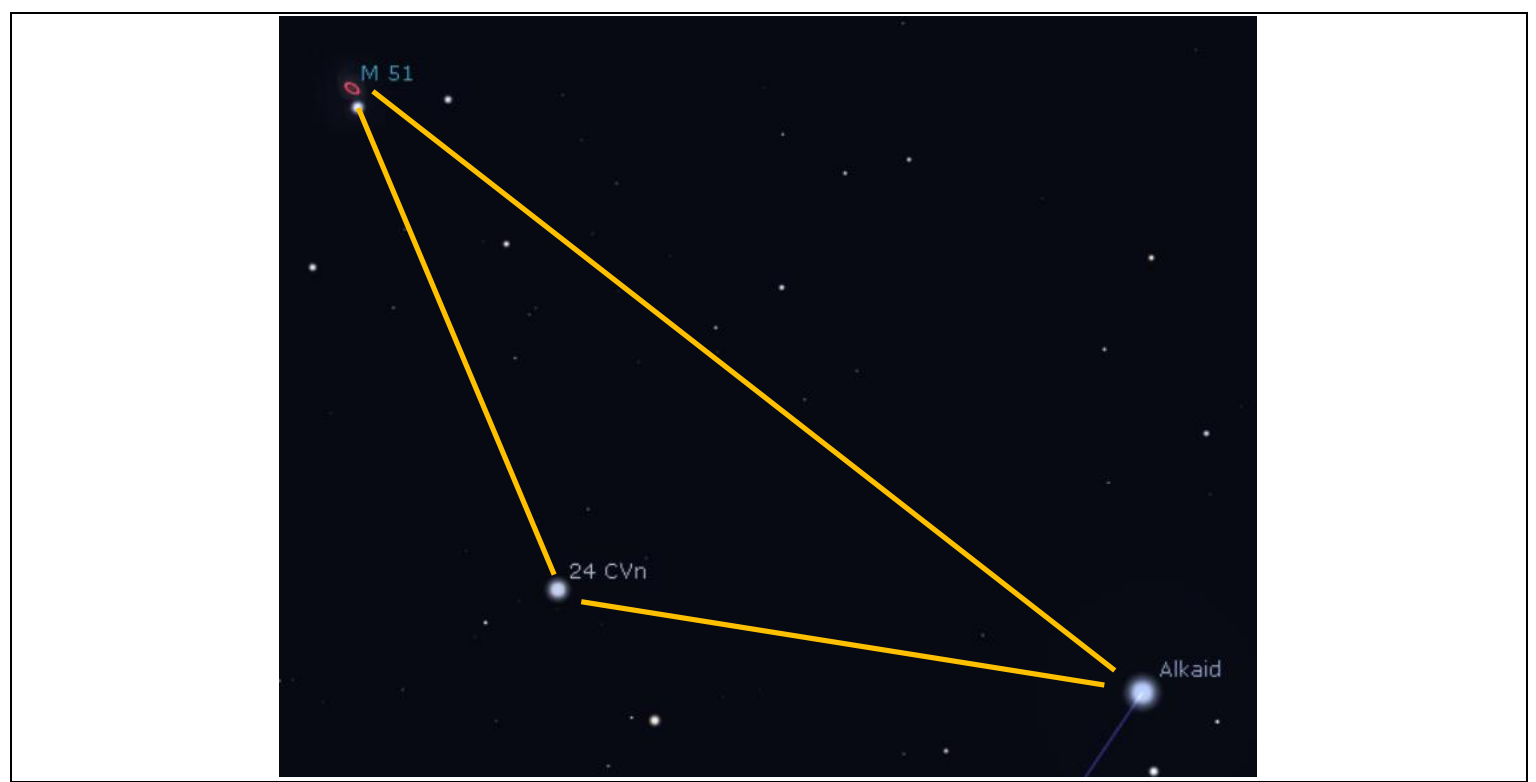

Figura 24: Star Hopping para localizar M-51.

Fonte: adaptado de Basey (2018).

Exemplo 2: M-5

O ponto de partida para localizar M-5 é compreender que ele situa-se entre duas estrelas muito brilhantes: Arcturus (Boieiro) e Antares (Escorpião), quase em linha reta entre elas, como mostra a Figura 25 a seguir: 


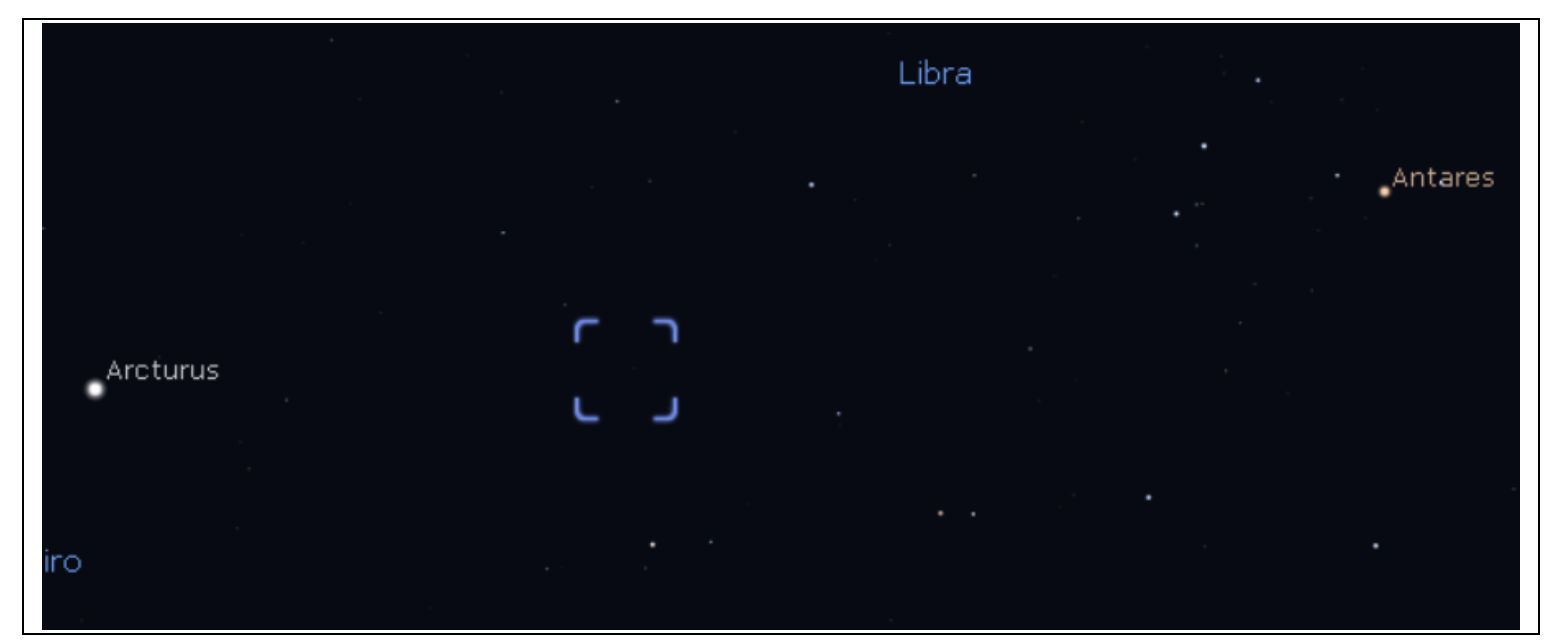

Figura 25: M-5, entre Arcturus e Antares.

Fonte: elaborada pelos autores.

Partindo de Arcturus, é possível "saltar" por estrelas de maior brilho, até se aproximar de M-5, como mostra a Figura 26 a seguir:

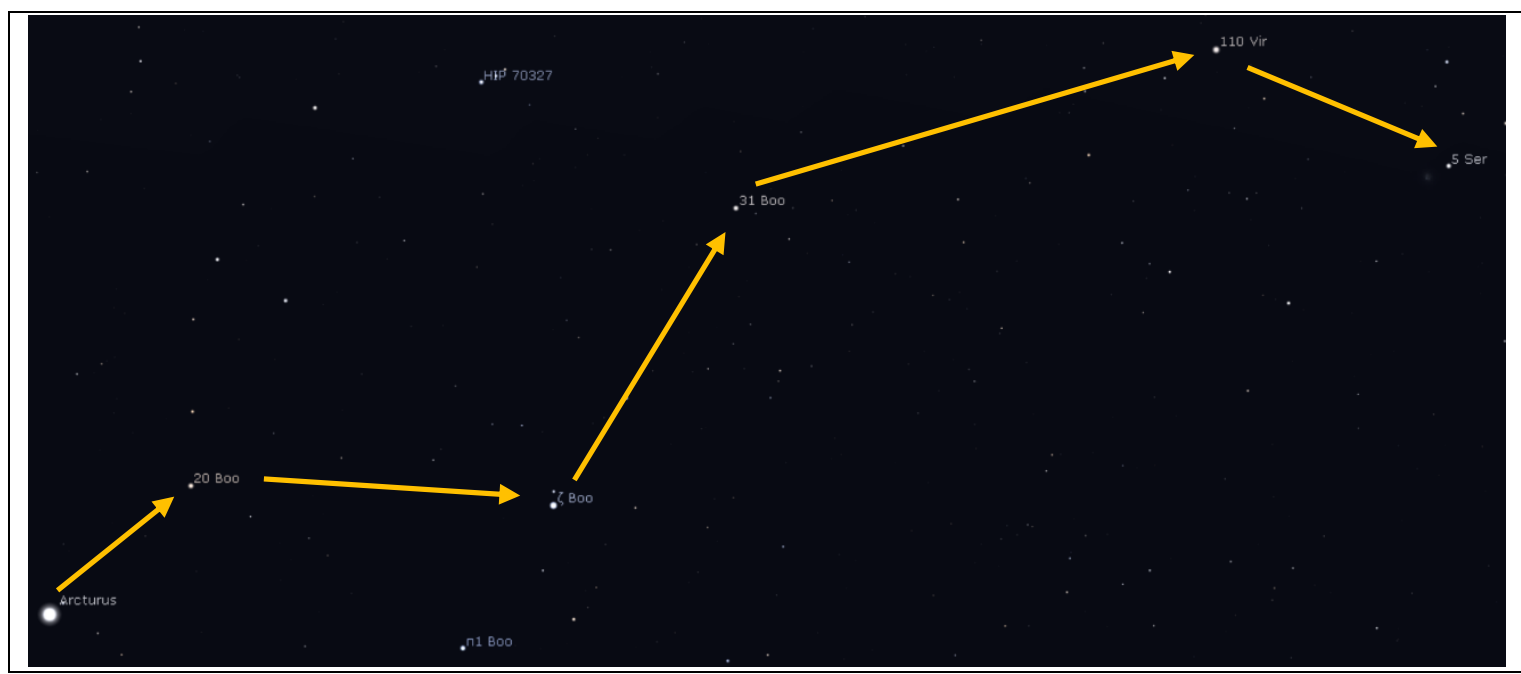

Figura 26: Star Hopping entre Arcturus e M-5.

Fonte: elaborada pelos autores.

Além disso, após chegar em 110 Vr será possível mentalizar um arco formado por estrelas brilhantes, o que ajuda o astrônomo a ter certeza de estar "indo para o lugar certo", como mostra a Figura 27. 


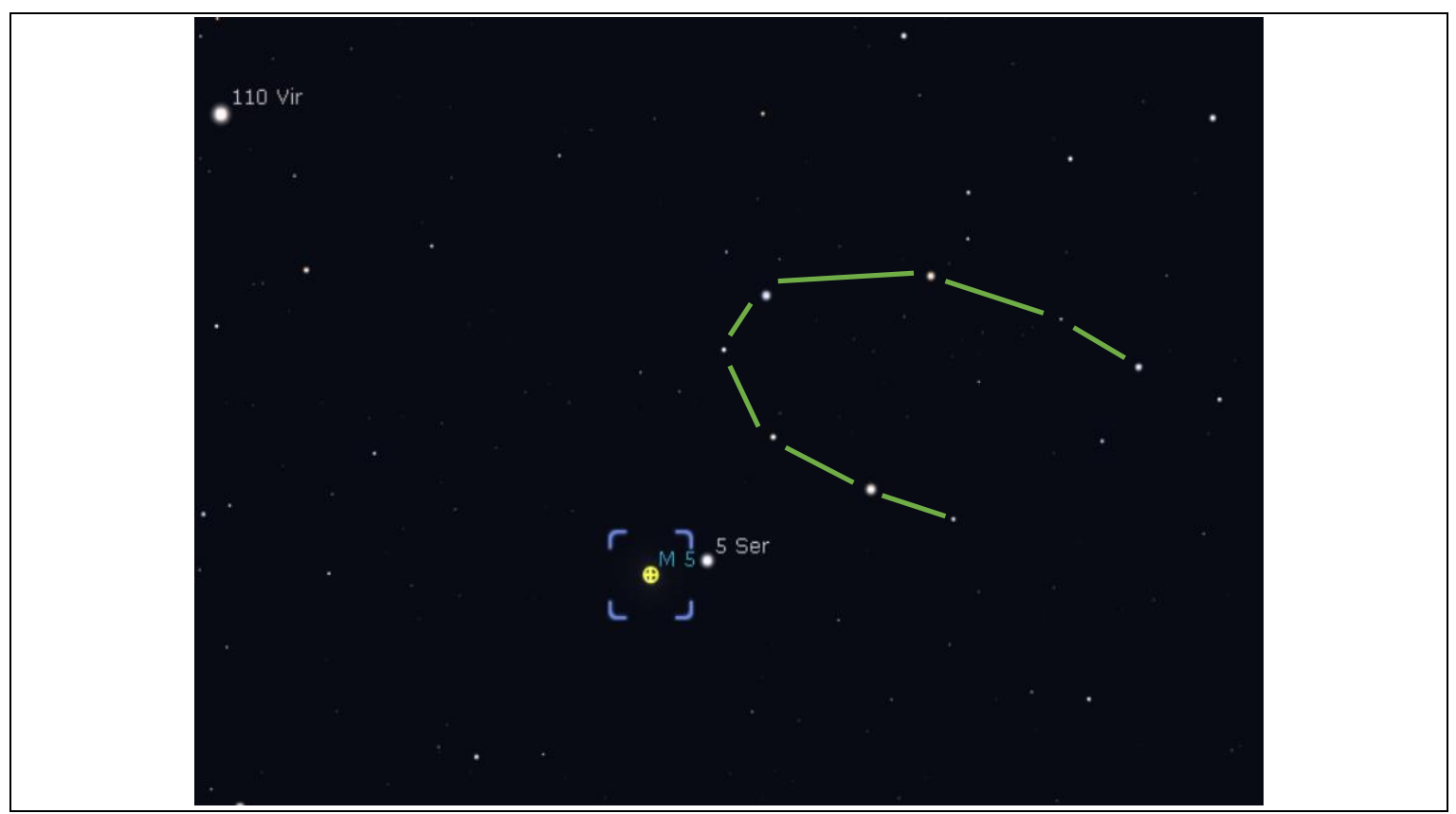

Figura 27: Proximidades de M-5.

Fonte: elaborada pelos autores.

\section{Dica 12: utilize sua visão periférica}

Uma vez que os objetos de céu profundo são difusos, nem sempre você consegue enxergá-los facilmente. Uma dica muito útil, dada por Almeida (2021), envolve o uso da visão periférica: use o "canto do olho" para observar pela ocular, caso não esteja enxergando adequadamente o objeto em questão, pois esta região do olho é muito mais sensível à luz.

\subsection{Respeitando a Ciência Astronômica}

\section{Dica 13: seja metódico}

A dica é autoexplicativa: adote critérios rígidos para seus registros. Afinal de contas, cada registro observacional é um modelo que busca retratar, ainda que de forma simplificada, a realidade.

Pronto para iniciar sua jornada pelo céu profundo?

\section{Mãos à obra!}




\section{BIBLIOGRAFIA}

ALMEIDA, G. As 10 Maiores Dificuldades do Recém-Chegado à Astronomia Amadora.

Disponível

em:

<https://www.uc.pt/iii/romuloccv/recursos_multimedia/artigos_apresentacoes_ci entificas/docs/10_maiores_dificuldades_do_principiante.pdf >. Acesso em: 7 abr. 2021.

BASEY, D. Star Hopping. Disponível em: <www.britastro.org/node/12846>. Acesso em: 10 abr. 2021.

BORTLE, J. E. Gauging Light pollution: The Bortle Dark-Sky Scale. Sky \& Telescope, 2006.

BRODY, D. S. How to Choose Binoculars for Astronomy and Skywatching. Disponível em: <https://www.space.com/27404-binoculars-buying-guide.html>. Acesso em: 2 abr. 2021.

CARREIRA, L. Binóculos para Astronomia. Disponível em: $<$ http://www.astrosurf.com/carreira/equipamento_binoc.html >. Acesso em: 2 abr. 2021.

CAVIN, J. D. The Amateur Astronomer's Guide to the Deep-Sky Catalogs. New York: Springer, 2012.

COMPANY SEVEN. Company Seven. Disponível em: <http://www.company7.com/library/unitron/unitron_114.html?hcb=1>. Acesso em: 10 abr. 2021.

CRATO, N. Como escolher binóculos. Disponível em: $<$ https://www.uc.pt/iii/romuloccv/recursos_multimedia/artigos_apresentacoes_ci entificas/artigos_divulgacao_cientifica_nuno_crato/como_escolher_binoculos>. Acesso em: 2 abr. 2021.

EARTH SKY. The Large Magellanic Cloud, our galactic neighbor. Disponível em: $\quad<$ https://earthsky.org/clusters-nebulae-galaxies/the-large-magellaniccloud>. Acesso em: 19 abr. 2021.

FRANKNOI, A.; MORRISON, D.; WOLFF, S. C. Astronomy. Houston: OpenStax, 2016.

GARGAGLIONI, S. Poluição luminosa e a necessidade de uma legislação. ComCiência, n. 112, p. 1-5, 2009.

HARRINGTON, S. N. 250+ Deep-Sky Objects Visible with $7 \times 35$ Binoculars and the Naked-Eye, 2018. Disponível em: <http://www.bridgendastro.org.uk/guides/Deep-

Sky\%20Objects\%20for\%20Binoculars\%20and\%20the\%20Naked-Eye.pdf>. Acesso em: 2 abr. 2021 
HENDRICKS, J. Astronomy: a beginner's guide to space. 2. ed. Online: Independent Publisher, 2015.

KERSTE, A. Astronomy on a Budget with Binoculars. Massenbachhausen: A. Kerste, 2018.

KING, B. How Dark Is Your Night Sky?Sky \& Telescope, 2018. Disponível em: $<$ https://skyandtelescope.org/observing/how-dark-is-your-night-sky/>. Acesso em: 5 abr. 2021

LIGHT POLLUTION MAP. Light Pollution Map. Disponível em: <https://www.lightpollutionmap.info>. Acesso em: 10 abr. 2021.

MACHHOLZ, D. The Observing Guide to the Messier Marathon: a Handbook and Atlas. New York: Cambridge University Press, 2002.

MARAN, S. P. Astronomia para Leigos. Tradução: Ricardo Sanovick. Rio de Janeiro: Alta Books, 2011.

NASA. APOD: 2006 January 9 - M45: The Pleiades Star Cluster. Disponível em: <https://apod.nasa.gov/apod/ap060109.html>. Acesso em: 19 abr. 2021.

NASA. Horsehead Nebula. Disponível em: <https://www.nasa.gov/multimedia/imagegallery/image_feature_89.html>.

Acesso em: 19 abr. 2021.

NASA. APOD: 2009 November 26 - M78 Wide Field. Disponível em: <https://apod.nasa.gov/apod/ap091126.html>. Acesso em: 19 abr. 2021.

NASA. 30 Doradus: The Growing Tarantula Within. Other. Disponível em: $<$ https://www.nasa.gov/mission_pages/chandra/multimedia/tarantula_nebula.ht ml>. Acesso em: 19 abr. 2021.

NASA. Messier $3 . \quad$ Disponível em: <http://www.nasa.gov/feature/goddard/2017/messier-3>. Acesso em: 19 abr. 2021a.

NASA. Messier 57 (The Ring Nebula). Disponível em: $<$ https://www.nasa.gov/feature/goddard/2017/messier-57-the-ring-nebula>. Acesso em: 19 abr. 2021b.

NASA. Andromeda Galaxy. Disponível em: <https://images.nasa.gov/detailsPIA04921 >. Acesso em: 19 abr. 2021a.

NASA. History of Hubble Space Telescope (HST). Disponível em: <https://images.nasa.gov/details-0700065>. Acesso em: 19 abr. 2021b.

OLIVEIRA, F. A.; LANGHI, R. Uma Proposta de Ensino de Astronomia por Meio da Abordagem Temática: poluição luminosa como tema. Anais... Anais... In: SIMPÓSIO NACIONAL DE EDUCAÇÃO EM ASTRONOMIA. Rio de Janeiro:

2011Disponível

em: 
<http://snea2011.vitis.uspnet.usp.br/sites/default/files/SNEA2011_TCP17.pdf>. Acesso em: 5 abr. 2021

PICAZZIO, E. (ED.). O Céu Que Nos Envolve. São Paulo: Odysseus, 2011.

PUGH, P. Observing the Messier Objects with a Small Telescope. New York: Springer, 2012.

RIDPATH, I. Guia Ilustrado Zahar: Astronomia. 4. ed. Rio de Janeiro: Zahar, 2014.

SANTIAGO, B. Observação Astronômica. Porto Alegre, 2021. Disponível em: <http://www.if.ufrgs.br/oei/santiago/fis02014/astpos.pdf>. Acesso em: 1 abr. 2021.

SERONIK, G. The Messier catalog: a binocular odyssey: try this minimalist approach to sharpen your observing skills and enhance your enjoyment. Sky \& Telescope, v. 124, n. 4, p. 68, 2012.

SLOTEGRAAF, A. Deep Sky Observer's Companion, 2008. Disponível em: <https://assa.saao.ac.za/wp-content/uploads/sites/23/2013/10/DOC13.pdf>.

Acesso em: 2 abr. 2021

STOYAN, R. et al. Atlas of the Messier Objects - Highlights of the Deep Sky. Cambridge: Cambridge University Press, 2008.

TELESCÓPIOS. Telescópios - TeleCalc. Disponível em: <https://www.telescopiosastronomicos.com.br/telecalc.html>. Acesso em: 10 abr. 2021.

TELLESCÓPIO.COM. Determinando o Seeing e a Transparência do Céu. Disponível em: <https://tellescopio.com.br/determinando-seeing-transparencia>. Acesso em: 7 abr. 2021.

ZOTTI, G.; WOLF, A. Stellarium 0.20.2 User GuideStellarium.Org, , 2020. 